\title{
Probabilistic Tsunami Hazard Analysis for Western Makran Coasts, Southeast Iran
}

\section{Hamid Zafarani}

International Institute of Earthquake Engineering and Seismology

Leila Etemadsaeed ( $\nabla$ etemadsaeed@iiees.ac.ir)

International Institute of Earthquake Engineering and Seismology https://orcid.org/0000-0001-9150-

0497

\section{Mohammad Rahimi}

University of Tehran

Navid Kheirdast

International Institute of Earthquake Engineering and Seismology

\section{Amin Rashidi}

Savoie University: Universite Savoie Mont Blanc

\section{Yu-Lin Tsai}

National Central University

\section{Anooshiravan Ansari}

International Institute of Earthquake Engineering and Seismology

\section{Mohammad Mokhtari}

International Institute of Earthquake Engineering and Seismology

\section{Morteza Eskandari-Ghadi}

University of Tehran

\section{Research Article}

Keywords: Tsunami, Makran subduction zone, Probabilistic hazard analysis, Heterogeneous slip distribution, Earthquake recurrence

Posted Date: February 4th, 2022

DOI: https://doi.org/10.21203/rs.3.rs-1317527/v1

License: (9) This work is licensed under a Creative Commons Attribution 4.0 International License. Read Full License 


\title{
Probabilistic Tsunami Hazard Analysis for Western Makran Coasts, Southeast Iran
}

\author{
Hamid Zafarani ${ }^{1}$, Leila Etemadsaeed ${ }^{2}$, Mohammad Rahimi ${ }^{3}$, Navid Kheirdast ${ }^{1}$, Amin Rashidi ${ }^{4}$ \\ Yu-Lin Tsai ${ }^{5}$, Anooshiravan Ansari ${ }^{1}$, Mohammad Mokhtari ${ }^{1}$, Morteza Eskandari-Ghadi ${ }^{3}$ \\ ${ }^{1}$ International Institute of Earthquake Engineering and Seismology (IIEES), Tehran, Iran \\ ${ }^{2}$ International Institute of Earthquake Engineering and Seismology (IIEES), Tehran, Iran, Etemadsaeed@iiees.ac.ir \\ ${ }^{3}$ School of Civil Engineering, College of Engineering, University of Tehran, Tehran, Iran \\ ${ }^{4}$ LAMA UMR 5127 CNRS, Université Savoie Mont Blanc, Campus Scientifique, 73376, Le Bourget-du-Lac, France \\ ${ }^{5}$ Graduate Institute of Hydrological Oceanic Sciences, National Central University, Taoyuan City, Taiwan
}

\section{Acknowledgment}

The present study was carried out within the frame-work of the project "Tsunami and Seismic hazard assessment for the Makran region." Funding for this project was provided by the Plan and Budget Organization of the Islamic Republic of Iran (PBO). Our sincere thanks are due to the staff of this organization for their support: Dr. Javad Ghanefard, Eng. Ali-Reza Totonchi, and Eng. Hamid-Reza Khashei.

(1)

(3)

4

45

4

49




\title{
Probabilistic Tsunami Hazard Analysis for Western Makran Coasts, Southeast Iran
}

52

\begin{abstract}
Makran subduction zone, along the southern coasts of Iran and Pakistan has a wide potential seismogenic zone and may be capable of generating large magnitude $(M \sim 9)$ tsunamigenic earthquakes. Considering ambiguities exist in tsunamigenic source characterization for subduction megathrusts like Makran, where detailed geologic, seismic, and geodetic data are insufficient, the probabilistic tsunami hazard analysis (PTHA) is the most prevalent approach to handle uncertainties and estimate more reliable tsunami hazard. Here, PTHA is performed for the coastal region of the western Makran, southeastern Iran. Using the logic tree approach, we have considered the uncertainty of maximum seismic magnitude, earthquake occurrence model, continuity of seismic zone, seismic coupling coefficient, depth of rupture, presence or absence of splay faults, fault locations, and fault slip distribution in PTHA calculation for the western Makran region. We have derived uniform tsunami hazard maps for two return periods of 475 and 2475 years for two confidence levels, the mean and the 84th percentile. Ground subsidence effects are also evaluated in a probabilistic manner. According to the PTHA results, Chabahar and Sirik towns are at the highest and lowest tsunami risk, respectively.
\end{abstract}

Keywords: Tsunami, Makran subduction zone, Probabilistic hazard analysis, Heterogeneous slip distribution, Earthquake recurrence

\section{1- Introduction}

Taking into account the catastrophic consequences of recent large magnitude (M 9) tsunami-generating earthquakes (i.e., the 2004 Indian Sumatra-Andaman and the 2011 Japan Tohoku earthquakes); it is crucial to perform risk analysis studies for tsunami-prone regions. The first step for a risk analysis study is to conduct a tsunami hazard assessment to evaluate coastal tsunami heights from tsunamigenic source models.

There are two main approaches to perform a tsunami hazard assessment: deterministic and probabilistic. The deterministic approach is usually conducted for a formidable scenario that can pose the largest hazard to the region of interest. However, the deterministic technique might cause unanticipated errors, such as determining an inappropriate worst-case scenario (i.e., underestimated or overestimated). On the other hand, from an economic point of view, the assumption of a biggest or worst possible scenario might not be suitable for conventional design goals or strategies, as buildings and facilities have limited lifespans. Thus, a probabilistic tsunami hazard analysis (PTHA) considering in a comprehensive manner both epistemic (associated to our limited knowledge about things which are constant in time) and aleatory or inherent (associated to natural variations that occur between different events) uncertainties (Abrahamson and Bommer 2005) becomes a better option for a tsunami hazard assessment.

The Makran subduction zone (MSZ) (Fig. 1), formed by northward motion of Arabian plate beneath the Eurasia plate, has a historical catalog of large earthquakes and associated tsunamis (e.g., the Makran tsunami of 1945 with death toll near 4,000).

The MSZ is divided into two distinct segments, eastern and western Makran (Byrne et al. 1992). The eastern segment hosted several historical large magnitude events at 1765, 1810 and 1945 (Ambraseys and Melville 1982), but the western segment has been quiescent at least in the past 300 years. An ambiguous report of a large earthquake at 1483 was criticized by Musson (2009) and attributed to moderate shallow crustal earthquakes in the neighborhood regions. However, the possibility of a large earthquake on the western segment or a huge event resulting from a cascading rupture across two segments cannot be ruled out (Musson 2009). Penney et al. (2017), showed that the subduction interface in the western Makran may be locked, accumulating elastic strain, and move in megathrust earthquakes (see Frohling \& Szeliga, 2016; Pajang et al., 2021), though its seismic coupling is reported to be weak (Ghadimi et al. 2021, submitted). 

and there are several PTHA for the Makran coastlines.

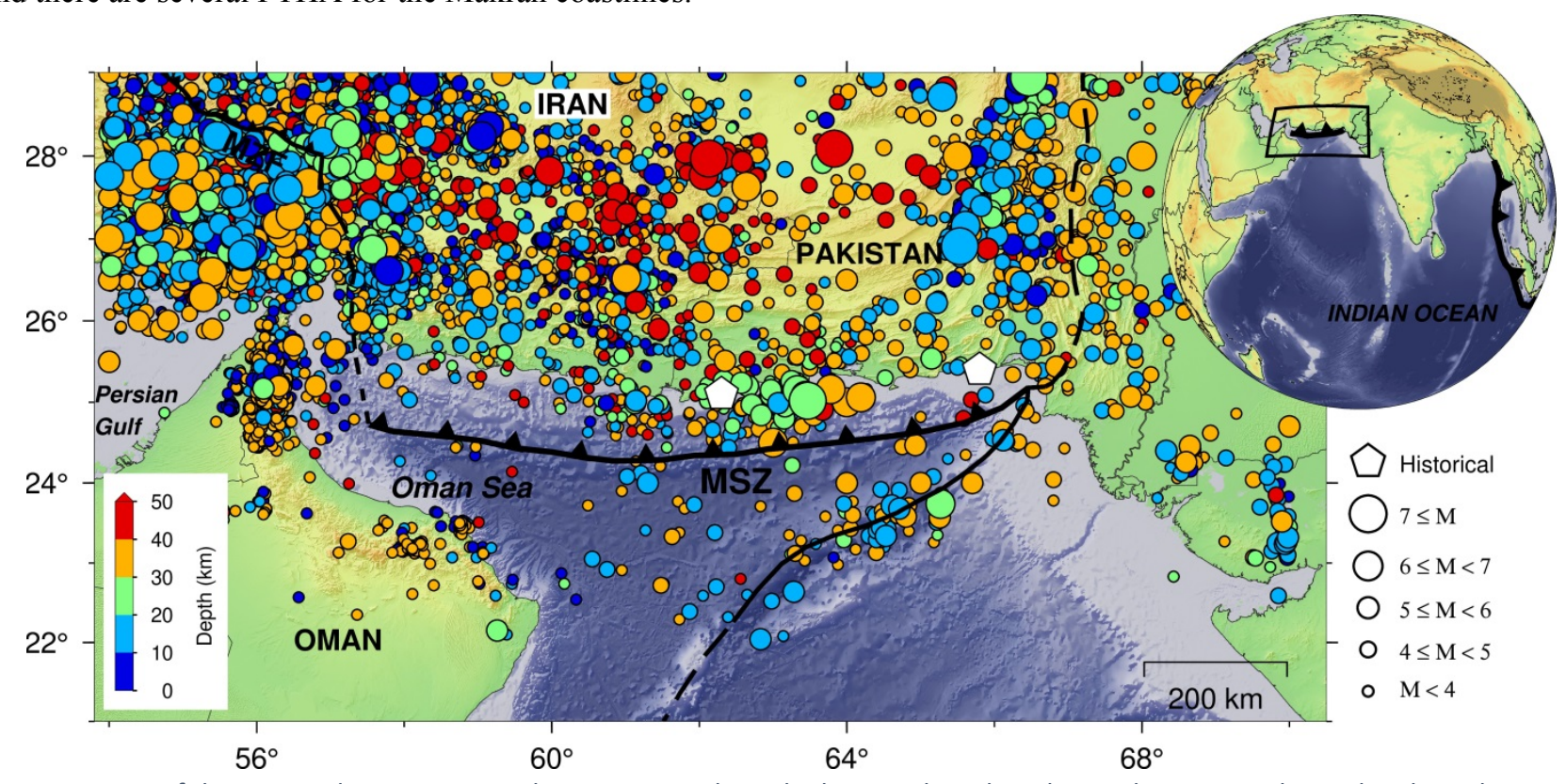

Fig. 1 Location of the MSZ and its seismicity. The pentagons show the historical earthquakes in this region. The circles show the occurred earthquakes from 1900 to 2019. The radius of a circle presents the magnitude of an earthquake. The color shading indicates the focal depths in $\mathrm{km}$

A list of these studies and their specifications is summarized in Table 1. They have been conducted at different scales of global, regional and local and different levels of detail were applied to describe the subduction geometry, fault slip distribution and other technical factors. A major drawback of some of these studies is that the seismicity rate was used instead of long-term fault slip rate to constrain the recurrence rates in the Gutenberg-Richter (GR) model (see section 2-2). Moreover, they ignored the important uncertainties regarding the recurrence model or Maximum magnitude and updip rupture depth.

The first PTHA research for Makran was conducted by Burbidge et al. (2009). They produced probabilistic tsunami hazard maps for the Indian Ocean countries, including Iran, considering the effects of tsunamis generated by the Makran, Sumatra-Andaman, and South Sandwich subduction zones. They presented their results as annual probabilities of exceeding certain tsunami wave amplitude in the water depth of $100 \mathrm{~m}$. Although not explicitly mentioned, it seems that the coupling factor in this study has been taken into account with the technique in which the rate of earthquake occurrence for each subduction zone is determined based on the percentage of the global subduction seismicity. Activity rates for each subduction zone, defined as the fraction of the global subduction zone seismicity that would be expected on each zone, was calculated based on the ratio of its length to the length of all tsunamigenic subduction zones in the world. The main problem in this technique is the assumption that the coupling factor for any given subduction zone is not significantly different from the global average along megathrusts In Burbidge et al. (2009) study, three possible rupture areas were considered for each modeled earthquake using the empirical scaling relations of Wells and Coppersmith (1994), which is not a subduction zone-specific relationship.

Following the study of Burbidge et al. (2009), several articles have been conducted on the PTHA in the MSZ. Using a limited mixed earthquake catalog of the Makran region including shallow crustal, interface and intraplate events to constrain the truncated Gutenberg-Richter (TGR) recurrence relation, Heidarzadeh and Kijko (2011) defined three scenarios with identical fixed magnitude ( $\mathrm{Mw}$ 8.1) in the eastern, central and western Makran for a probabilistic tsunami hazard assessment along the coasts of Iran, Oman and Pakistan. They considered fixed magnitude, location, and depth and also uniform slip distribution for each scenario.

Løvholt et al. (2012) conducted a tsunami hazard assessment on the global scale including the MSZ. Hoechner et al. (2016) used the TGR recurrence model and Makran instrumental era catalog in computing the exceedance rate of 
tsunami height for Makran coastlines. The slip rate of the MSZ was ignored in their analysis and they used the general seismicity of the whole Makran region without any distinction between shallow crustal, interface and intraplate earthquakes.

El-Hussain et al. $(2016,2018)$ constructed some source models with different magnitudes along the MSZ and used the logic-tree procedure and probabilistic method to estimate the tsunami hazard along the Oman shorelines. They only employed the TGR recurrence model for magnitude-frequency and assumed uniform slip on earthquake sources. Also, while not considering the coupling coefficient, probabilistic results were presented for the coasts of Oman.

In another global-scale study, Davies et al. (2017) performed a probabilistic tsunami hazard assessment. They assigned three slip rates of 5.4, 9.0 and $13.0 \mathrm{~mm} /$ year for the Makran fault. Assuming a convergence rate of 20 $\mathrm{mm} /$ year, the resulting coupling factors are about $0.3,0.5$ and 0.7 . They also assumed three maximum magnitudes of 8.1, 8.8 and 9.5. They did not take into account the segmentation of the MSZ into the western and eastern segments.

Another probabilistic tsunami hazard assessment was done by Am. Rashidi et al. (2020b) for a range of heterogeneous slip distributions of the MSZ. Tsunami hazard curves and probability maps for the region were their outcome. They used the TGR recurrence model and a fixed non-planar geometry for the MSZ. The effect of seismic coupling was not a part of their computations.

In general, probabilistic tsunami hazard assessment is a multidisciplinary problem which contains tsunami numerical modeling and probabilistic calculations for the earthquake source and tsunami wave amplitude. This would require different experts in various fields of seismology, seismotectonics, geodesy, probability and statistics, hazard assessment, and numerical hydrodynamic modeling. So far, a comprehensive study using the knowledge of the above various fields and combining them together in a logical and scientific format, has not been done at a regional-scale for the western Makran coastline. Present study tries to resolve and address the weaknesses and limitations of the previous studies as much as possible.

In this study, we consider the uncertainty of maximum seismic magnitude, earthquake occurrence models, continuity of seismic zone, seismic coupling coefficient, depth of rupture, presence or absence of splay faults, fault locations, and fault slip distribution in PTHA for the MSZ. To clarify the importance of considering these uncertainties, it is worth noting that in modeling the tsunami observed after the only instrumental era large interface event in this region, i.e. the 1945 Makran earthquake with a magnitude of 8.1, there are significant differences between the hypotheses of various studies (e.g., Heidarzadeh et al. 2008, 2009; Jaiswal et al. 2009; Neetu et al. 2011). Considering homogeneous slip model, and presence or no presence of splay faulting (reaching the rupture to the seabed), are among the main reasons for the failure to model the observed tsunami wave height of this earthquake. This would place another emphasis on the key role of nonhomogeneous slip distribution to have a more reliable estimate of expected tsunami wave amplitudes, a factor that was ignored in most of the past PTHA studies (Table 1). In addition to non-uniform slip, the present study incorporates multiple assumptions including different top depths of the rupture, fault-rupture-scaling model, the effect of coupling in seismic activity of the region, and a more precise bathymetry data (see sections 2). Earth subsidence effects are also evaluated in a probabilistic manner in this study for the first time.

It should be mentioned that our study only includes earthquake scenarios from the MSZ. As shown by the simulation results in Okal and Synolakis (2008), far-field scenarios have only mild effects on the Makran coasts and are thus excluded from our study.

\section{2- Uncertainties in western Makran tsunami modeling}

There are both aleatory and epistemic uncertainties in a PTHA study, though sometimes the margin between these two categories is vague and depends on personal opinion.

Aleatory uncertainties in fact indicate the natural randomness inherent in the nature of phenomena, whereas epistemic uncertainties are due to a lack of information and human knowledge about the natural processes. The logic tree is an efficient tool for considering epistemic uncertainties in probabilistic hazard and risk analysis studies, first introduced to the field by Kulkarni et al. (1984). One of the most important parameters in determining the behavior 
and output of the logic tree is the weighting done by experts into its various branches, which represent different hypotheses in modeling. The branch weights in a logic tree represent the degree of belief of experts in each element of models.

In the next section, by expression the uncertainties in tsunami hazard analysis in the MSZ; the considered logic tree for this study (Fig. 2) is introduced. It should be noted that, the dip-angle of the subduction interface of the MSZ could be another source of uncertainty and was a matter of debate for a long time (see e.g. Byrne et al. (1992), Maggi et al. (2000), Kopp et al (2000), Penny et al. (2017)). Penny et al. (2017) implemented well-located earthquakes in the region, and receiver functions from local seismometers to constrain the range of possible interface dips. They reported maximum average dips of $\sim 11 \circ$ in the western, $\sim 9 \circ$ in the central and $\sim 8 \circ$ in the eastern Makran region, respectively. In a recent study, using the wide-angle reflection technique along three crustal-scale, trench-perpendicular, deep seismic sounding profiles, Haberland et al. (2020) has delineated the position and the dip of the subducting plate (oceanic Moho). According to Haberland et al. (2020) the crustal structure and the very gentle dip $\left(\sim 8^{\circ} \pm 2^{\circ}\right)$ of the subducting plate suggest a very wide contact zone, potentially allowing very wide asperities. In the light of aforementioned studies, here a fixed value is used for the dip of the subduction interface which is important for assessing tsunami wave height generated by different seismic scenarios.

\section{2-1 Maximum seismic magnitude of the MSZ}

For years, seismologists believed that some subduction zones would never be able to produce earthquakes of magnitude Mw 9.0 or greater (Ruff and Kanamori 1980). However, after the 2004 Indonesia Mw 9.2 and the 2011 Japan Mw 9.0 earthquakes, the general view of seismologists is that all or at least most of the subduction zones are capable to produce an earthquake of magnitude $\mathrm{Mw} 9.0$, in a global analogy context. Generally, there are two main approaches for determination of the maximum magnitude (Mmax): those that are based on an earthquake catalog (maximum observed magnitude plus an increment) and those based on empirical scaling relations through a seismic source zone model. The second method, in the simplest way uses fault length, while a more accurate alternative is to use the rupture area (which is proportional to the accumulated moment, Hanks and Kanamori 1979). Due to lack of historical events, except the $1945 \mathrm{Mw} 8.2$ earthquake in the eastern Makran, here we emphasize more on the second approach, which implies adopting the concept of global analogy of Mmax for all subduction zones (Meletti et al. 2010). As the seismic moment released in an earthquake is a function of rupture area, so assuming an average shear modulus of $\mu=30 \mathrm{GPa}$ for subduction zones (Hanks and Kanamori 1979), average dip angle of $8^{\circ}$ and length of 900 $\mathrm{km}$ for the entire MSZ (or even the eastern or western segment of the MSZ), occurrence of an earthquake magnitude equal to or greater than $\mathrm{Mw} 9.0$ is possible.

Moreover, thermal modeling performed by Smith (2012) to determine areas with temperatures above $150^{\circ} \mathrm{C}$ in sediments, showed that the occurrence of earthquakes with magnitude up to Mw 9.2 in the MSZ is possible. According to the Smith's (2012) modeling, the Makran crust reaches a temperature of $350^{\circ} \mathrm{C}$ at a depth of $60 \mathrm{~km}$ and a temperature of $450^{\circ} \mathrm{C}$ at a depth of $75 \mathrm{~km}$. Therefore, with a length of about $800 \mathrm{~km}$ and a rupture width of about $200 \sim 350 \mathrm{~km}$, a magnitude Mw 9.0 to 9.2 is proposed as the maximum magnitude of the MSZ in the worst-case scenario. In another study, by modeling deformation based on the GPS data to determine the downdip locking width, Frohling and Szeliga (2016a) proposed a maximum magnitude of Mw 8.8 for the entire length of the MSZ. Also, considering the length of more than $900 \mathrm{~km}$ for the MSZ and using empirical scaling relationships specific to subduction zones, such as that proposed by Skarlatoudis et al. (2016), occurrence of earthquakes with a magnitude of about Mw 9.1 9.2 is probable in the MSZ.

On the other hand, study of the location of megathrust subduction earthquakes shows that earthquakes with a magnitude of Mw 9.0 and more occurred in places such as the MSZ that have previously experienced quiescent periods with few numbers of moderate earthquakes (Hort et al., 2011).

In a recent two-dimensional numerical study of megathrust earthquakes in subductions (magnitude greater than Mw 8.5), Muldashev and Sobolev (2020) showed that the dip angle of the subduction plate has the greatest effect on the maximum expected magnitude of a subduction zone. Hence, the lower the dip angles of the subduction zone, the 
223 greater potential for producing larger megathrust earthquakes. Therefore, taking into account low dip angle $\left(\sim 8^{\circ}\right)$ of 224 the subduction plate in the MSZ, there is potential for occurrence of larger megathrust earthquakes. 
Table 1. A summary of PTHA studies conducted for the MSZ

\begin{tabular}{|c|c|c|c|c|c|c|c|c|c|}
\hline Study & Output(s) & Modeling & $\begin{array}{c}\text { Slip } \\
\text { distribution }\end{array}$ & $\begin{array}{l}\text { Bathymetry } \\
\text { resolution }\end{array}$ & $\begin{array}{l}\text { Magnitude } \\
\text { Range }\end{array}$ & Fault scaling relationship & $\begin{array}{c}\text { Earthquake } \\
\text { recurrence } \\
\text { model }\end{array}$ & Coupling & $\begin{array}{c}\text { Scale of } \\
\text { study }\end{array}$ \\
\hline $\begin{array}{l}\text { Burbidge et } \\
\text { al. (2009) }\end{array}$ & $\begin{array}{l}\text { Tsunami wave amplitudes } \\
\text { in water depth of } 100 \mathrm{~m}\end{array}$ & $\begin{array}{c}\text { Linear shallow water } \\
\text { wave equations (URSGA } \\
\text { model) }\end{array}$ & Uniform & $2 \operatorname{arc} \min$ & $\begin{array}{l}7.0-8.2 \\
\text { and } 9.1\end{array}$ & Wells and Coppersmith (1994) & TGR & $\begin{array}{c}\text { Average } \\
\text { coupling } \\
\text { for global } \\
\text { subduction } \\
\text { zones }\end{array}$ & Global \\
\hline $\begin{array}{l}\text { Heidarzadeh } \\
\text { and Kijko } \\
(2011)\end{array}$ & $\begin{array}{c}\text { Tsunami wave amplitudes } \\
\text { at coastline }\end{array}$ & $\begin{array}{c}\text { Nonlinear shallow water } \\
\text { wave equations } \\
\text { (TUNAMI-N2 model) }\end{array}$ & Uniform & 1 arc min & 8.1 & The 1945 Makran earthquake & TGR & $\begin{array}{c}\text { Not } \\
\text { included }\end{array}$ & Regional \\
\hline $\begin{array}{l}\text { Løvholt et al. } \\
\qquad(2012)\end{array}$ & $\begin{array}{l}\text { Tsunami wave amplitudes } \\
\text { at coast (water depth of } 0.5 \\
\mathrm{~m} \text { ) computed using } \\
\text { amplification factors from } \\
\text { water depth of } 50 \mathrm{~m}\end{array}$ & $\begin{array}{c}\text { Linear shallow water } \\
\text { wave equations } \\
\text { (GloBouss model) }\end{array}$ & Uniform & $2 \operatorname{arc} \min$ & Up to 8.4 & Wells and Coppersmith (1994) & TGR & $\begin{array}{c}\text { Not } \\
\text { included }\end{array}$ & Global \\
\hline $\begin{array}{l}\text { El-Hussain et } \\
\text { al. (2016) }\end{array}$ & $\begin{array}{c}\text { Tsunami wave amplitudes } \\
\text { at coastline }\end{array}$ & $\begin{array}{c}\text { Nonlinear shallow water } \\
\text { wave equations } \\
\text { (NSWING model) }\end{array}$ & Uniform & $30 \operatorname{arc~sec}$ & $7.9-9.1$ & - & TGR & $\begin{array}{c}\text { Not } \\
\text { included }\end{array}$ & Local \\
\hline $\begin{array}{l}\text { Hoechner et } \\
\text { al. (2016) }\end{array}$ & $\begin{array}{l}\text { Tsunami wave amplitudes } \\
\text { at coast (water depth of } 1.0 \\
\mathrm{~m} \text { ) computed based on } \\
\text { Green's law from } \\
\text { amplitudes in water depth } \\
\text { of } 50 \mathrm{~m}\end{array}$ & $\begin{array}{c}\text { Linear shallow water } \\
\text { wave equations } \\
\text { (easyWave model) }\end{array}$ & Non-uniform & $30 \operatorname{arcsec}$ & Up to 9.0 & Blaser et al. (2010) & TGR & $\begin{array}{c}\text { Not } \\
\text { included }\end{array}$ & Regional \\
\hline
\end{tabular}




\begin{tabular}{|c|c|c|c|c|c|c|c|c|c|}
\hline Study & Output(s) & Modeling & $\begin{array}{c}\text { Slip } \\
\text { distribution }\end{array}$ & $\begin{array}{l}\text { Bathymetry } \\
\text { resolution }\end{array}$ & $\begin{array}{l}\text { Magnitude } \\
\text { Range }\end{array}$ & Fault scaling relationship & $\begin{array}{l}\text { Earthquake } \\
\text { recurrence } \\
\text { model }\end{array}$ & Coupling & $\begin{array}{c}\text { Scale of } \\
\text { study }\end{array}$ \\
\hline $\begin{array}{l}\text { El-Hussain et } \\
\text { al. (2018) }\end{array}$ & $\begin{array}{l}\text { Tsunami wave amplitudes } \\
\text { at coastline }\end{array}$ & $\begin{array}{l}\text { Nonlinear shallow water } \\
\text { wave equations } \\
\text { (NSWING model) }\end{array}$ & Uniform & 30 arc sec & $7.5-8.8$ & - & TGR & $\begin{array}{l}\text { Not } \\
\text { included }\end{array}$ & Local \\
\hline $\begin{array}{l}\text { Davies et al. } \\
\quad(2017)\end{array}$ & $\begin{array}{l}\text { Tsunami wave amplitudes } \\
\text { at coast (water depth of } 0.5 \\
\mathrm{~m} \text { ) computed using } \\
\text { amplification factors and } \\
\text { Green's law from } \\
\text { amplitudes in water depths } \\
\text { of } 100 \mathrm{~m} \\
\end{array}$ & $\begin{array}{l}\text { Linear shallow water } \\
\text { wave equations (URSGA } \\
\text { model) }\end{array}$ & Uniform & 30 arc sec & $\begin{array}{l}7.5-8.1 \\
8.8-9.5\end{array}$ & Strasser et al. (2010) & TGR & $\begin{array}{c}\text { Different } \\
\text { scenarios } \\
\text { are } \\
\text { considered }\end{array}$ & Global \\
\hline $\begin{array}{l}\text { Am. Rashidi } \\
\text { et al. (2020b) }\end{array}$ & $\begin{array}{l}\text { Tsunami wave amplitudes } \\
\text { at coastline }\end{array}$ & $\begin{array}{l}\text { Nonlinear shallow water } \\
\text { wave equations } \\
\text { (COMCOT model) }\end{array}$ & Non-uniform & $30 \mathrm{arc} \mathrm{sec}$ & $9.06-9.12$ & Smith et al. (2012) & TGR & $\begin{array}{l}\text { Not } \\
\text { included }\end{array}$ & Regional \\
\hline This study & $\begin{array}{l}\text { Tsunami wave amplitudes } \\
\text { at coast (water depth of } 0.5 \\
\text { m) computed based on } \\
\text { Green's law from } \\
\text { amplitudes in water depths } \\
\text { of } 10 \text { and } 50 \mathrm{~m}\end{array}$ & $\begin{array}{l}\text { Nonlinear shallow water } \\
\text { wave equations } \\
\text { (COMCOT model) }\end{array}$ & Non-uniform & $\begin{array}{c}15 \operatorname{arcsec}(3 \\
\text { arc sec for } \\
\text { some areas) }\end{array}$ & $7.7-9.1$ & Skarlatoudis et al. (2016) & $\begin{array}{c}\text { TGR, Pure } \\
\text { Characteristics } \\
\text { model }\end{array}$ & $\begin{array}{c}\text { Computed } \\
\text { and } \\
\text { different } \\
\text { scenarios } \\
\text { are } \\
\text { considered }\end{array}$ & Regional \\
\hline
\end{tabular}




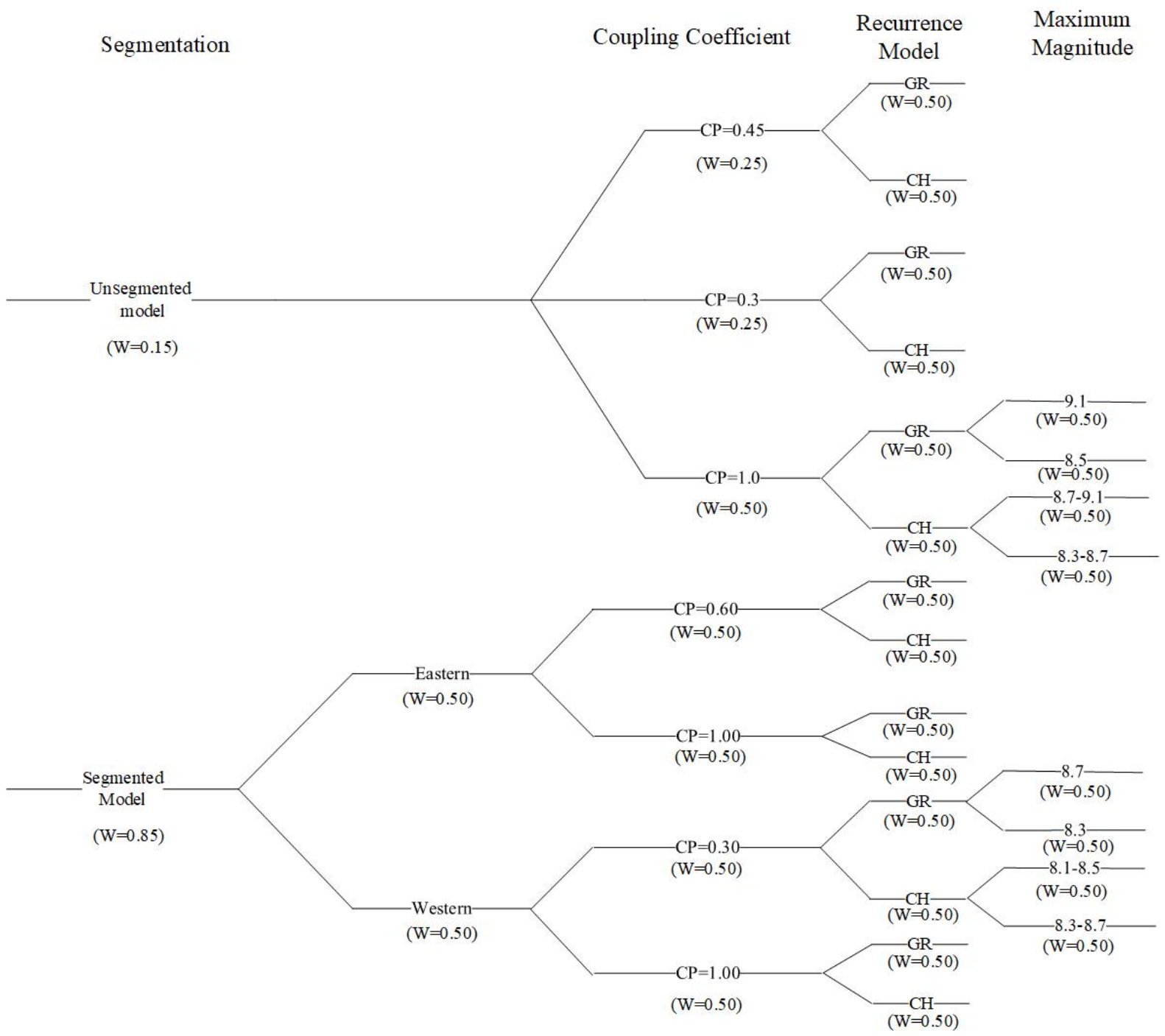

Fig. 2 The logic tree used in this study

Many earthquakes have been reported compared to smaller ones. Despite the extensive data for attempts have been made to obtain empirical scaling relationships between fault rupture dimensions and seismic magnitude based on past earthquakes data (Papazachos et al. 2004; Blaser et al. 2010; Strasser et al. 2010; Murotani et al. 2013; Skarlatoudis et al. 2016; Allen and Hayes 2017; Thingbaijam et al. 2017). One of the important points is whether the scaling relations, which are mainly constrained and developed by using smaller earthquake data, can also be attributed to megathrust earthquakes in subduction zones, while different characteristics of these large earthquakes in subduction zones, there is still low data to determine the rupture behavior of giant earthquakes (magnitude greater than 8.5). This limitation is especially evident in determining the width of the rupture plate (Skarlatoudis et al. 2016). Some researchers suggest rupture width saturation, meaning that the fault width does not change with increasing the earthquake magnitude after a certain value (Tajima et al., 2013; Skarlatoudis et al., 2016). However, the lack of data in this range of magnitude makes it difficult to draw final conclusions.

According to Strasser et al., (2010) it is important to consider more than one empirical scaling relationship to determine maximum magnitude from an epistemic uncertainty perspective. Therefore, in this study the possible maximum earthquake magnitude has been calculated with three scaling relationships of Skarlatoudis et al. (2016), Thingbaijam et al. (2017) and Allen and Hayes (2017), based on different assumptions regarding the fault rupture 
These three selected relations have considered more earthquakes than the other existing scaling relations, including very large recent earthquakes (for example, the 2011 Tohoku earthquake) and therefore are more reliable in this respect.

In this study, the selected scaling relationships are used with equal weight in determining the maximum

- Empirical scaling relationships based on magnitude-rupture area (considering two rupture area scenarios).

- Empirical scaling relationships based on magnitude-rupture width (considering two rupture width scenarios).

- Empirical scaling relationships based on magnitude-rupture length.

Therefore, if the rupture width (width of the locked area) is assumed between $80 \mathrm{~km}$ (minimum depth of 14 $\mathrm{km}$ and maximum depth of about $25 \mathrm{~km}$ ) and $185 \mathrm{~km}$ (minimum depth of $14 \mathrm{~km}$ and maximum depth of about 40-45 km), based on the selected empirical scaling relationships of subduction zones, the maximum possible magnitude for the two pessimistic and optimistic scenarios in each of the western, eastern and entire Makran logic tree branches will be $(8.7,8.7,9.1),(8.3,8.3,8.5)$, respectively. In this regard, the maximum moment magnitude in the GR models and the central magnitude in the pure characteristic model for each of the western, eastern, and entire Makran logic tree branches are selected equal to these values.

\section{2-2 Earthquake occurrence model}

In a PTHA study, an empirical model that gives the number of earthquakes with magnitude $m$ that occur within a year is needed to explain the magnitude-frequency distribution of earthquakes. In earthquake hazard studies, either the GR or the Characteristic-Earthquake models are commonly used. As pointed out by Davis et al. (2017), two modified version of GR models, that incorporate a maximum magnitude bounds are often used to characterize earthquake recurrences:

The Characteristic GR (Kagan 2002) as:

$$
\mathrm{GR}\left(\mathrm{m}_{w}\right)=f(x)=\left\{\begin{array}{rr}
10^{a-b \mathrm{~m}_{w},} & \mathrm{~m}_{w, \min } \leq \mathrm{m}_{w} \leq \mathrm{m}_{w, \max } \\
0, & \mathrm{~m}_{w}>\mathrm{m}_{w, \text { max }}
\end{array}\right.
$$

And the TGR as:

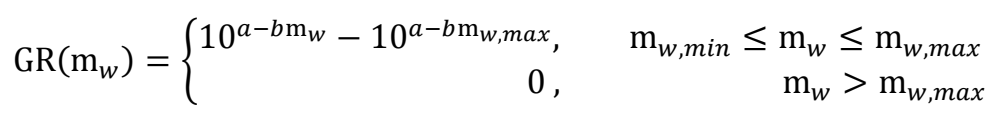

In the PTHA studies, the first model is usually called the Characteristic model since, like the well-known Characteristic model of seismic hazard studies (Youngs and Coppersmith 1985), its recurrence rate at Mmax is not exactly zero. On the other hand, the second model (i.e. TGR), also known as the exponential model, has a recurrence rate at Mmax, that is exactly zero.

The Characteristic model, also known as the "Maximum magnitude" model generates earthquakes only within a relatively narrow magnitude range (Stewart et al. 2002). As earthquakes of small to moderate magnitude that follow the GR distribution are unlikely to cause a tsunami (Thio et al (2007)) in addition to the TGR model, we also use a pure Characteristic model described above.

The Characteristic model is more consistent with the observed seismicity of the Makran region (lack of moderate to large events) and also does not require a b-value (see section 2-3). This is important from the viewpoint that some recurrence intervals resulted from a GR model, such as one earthquake with $M \geq 7.5$ every 30 years, which are reported by El-Hossein et al. (2016), cannot be validated at least through the last 200 years (Ambraseys \& Melville, 1982).

A pure characteristic recurrence model with a width parameter of 0.3-0.5 magnitude units (depending on the past seismicity) was used in a probabilistic Tsunami hazard study in Japan, representing characteristic earthquakes with a uniform distribution (Annaka et al. 2007).

Because only earthquakes with magnitudes greater than 7.5 can generate tsunamis, Thio et al. (2007) in another study on the probabilistic hazard of tsunamis in eastern Asia, rely solely on the pure Characteristic models. A similar study is linked to what is known as quiescent seismicity in the Cascadia region of eastern Canada and 
United States, where the GR model was not used; however, the recurrence model for the interface earthquakes was recognized as a pure characteristic model with a return period of 500 years for a $\mathrm{M}>9$ event and a return period of 100 years for a $\mathrm{M}>8$ event (Frankel et al. 2002).

Atkinson and Goda (2011) used an alternative version of pure Characteristic recurrence model, assuming a normal distribution with a mean of 8.5 and a standard deviation of 0.5 to calculate the recurrence rates for various moment magnitudes of the Cascadia subduction zone.

To constrain the recurrence models using fault slip rates, the following relationship between the annual rate of moment-release and earthquake recurrence rates is suggested by Anderson and Luco (1983):

$$
\dot{M}_{0}=\mu A S=\int_{m_{\min }}^{M_{\max }} M_{0}(m) \dot{n}(m) d m
$$

Where $\dot{n}(m)$ is the density function for earthquake occurrence rate, $\dot{M}_{0}$ denotes the annual rate of momentrelease, and $M_{0}(m)$ denotes the magnitude-seismic moment relationship proposed by Hanks and Kanamori (1979):

$$
M_{0}(m)=10^{1.5 m+9.05}
$$

It is worth noting that both the GR and the Characteristic models were favored in different studies when deciding on a recurrence model (Schwartz 1999; Pisarenko and Sornette 2004).

\section{2-3 b-value in Gutenberg-Richter model}

Following the discussion above, two recurrence models, namely the TGR and the pure Characteristic model (also referred to as Maximum magnitude recurrence model) are used in the current study. Therefore, to completely explain the seismicity in the Makran subduction region, we must obtain the b-value.

According to (Benito et al. 2012), in any subduction zone, three seismicity regimes, crustal, interface slab, and inslab, can cause earthquakes. In the Makran region, the lack of interface slab earthquakes is a significant limitation to using the GR recurrence relation. Unfortunately, due to a lack of data, seismicity parameters in the subduction zone are normally calculated using a combination of interface, inslab and crustal earthquakes. For example, Deif and El-Hussain (2012) and Hoechner et al (2016), combined earthquakes from all three seismic regimes and estimated the b-value to be 0.77 and 0.82 , respectively.

Another issue caused by the lack of earthquakes, as emphasized by Pisarenko and Sornette (2004), is weak constraint at the end tail of the GR distribution, where major tsunamigenic events occur. It's worth noting that the aforementioned issues also exist in other subduction zones, such as the Cascadia subduction zone, where seismic activity is currently low.

Since the lack of seismic activity prevents the calculation of the b-value in the Cascadia area, in a comprehensive study by BC Hydro (2012), its value was adopted from other studies around the world where the abundance of seismicity permits the calculation of the b-value. The absence of interface seismic data and the presence of a thick sediment layer (McAdoo et al. 2004) are common features of both the Cascadia and Makran subduction zones.

According to the GEM Faulted Earth Subduction Interface Characterization Project: Version 2.0 (Berryman et al. 2015), who processed seismicity data from subduction zones around the world and took into account the low rate of $\mathrm{M}>5.5$ earthquakes in Hikurangi, the Caribbean, Cascadia, and Makran, they suggested that the b-value for the interface slab in these regions is likely lower than the global average.

By reviewing the b-values reported world-wide, Wang et al (2016) allocated 0.7 to the north Taiwan subduction zone, Power et al (2013) used 0.75 for the Japan Trench, and GEM group (Berryman et al. 2015) used a range of 0.7-1.2 for subduction zones around the world. Note that in the GEM report, the b-value in Makran was assigned according to Bayrak et al (2002) who devised the b-value equal to 0.78. However, the combination of Zagros (a shallow crustal environment) and Makran earthquakes, which was disregarded in the GEM report, is a serious criticism of Bayrak et al (2002). 
We calculated the b-value by reviewing previous global studies and gathering seismic activity in the western and eastern MSZs. We obtained a b-value of 0.75 without distinguishing between shallow crustal and interface slab regimes, but excluding inslab events (Ah. Rashidi et al., 2020).

\section{2-4 Continuity of seismic zone}

The MSZ is an area with an approximate length of $1000 \mathrm{~km}$ which has been extended through the coast of Iran \& Pakistan from Strait of Hormuz to Karachi in Pakistan. According to (Heuret et al. 2011), when the length of subduction is below $\sim 500 \mathrm{~km}$, the large earthquakes is unlikely to happen. However, the observed amount of rupture length in past-longer subduction earthquakes was also limited to part of the total length of the subduction zone $(500 \sim 2000 \mathrm{~km})$. The reason for this discontinuity in rupture propagation, and consequently the limited rupture length, is that the complexity of the subducting plate (such as different sediment thicknesses, fracture zones, Seamounts, the presence of horst and Graben) and the strength of the upper plate cause local changes in friction along the length.

Although there are strong evidences of the segmentation of the MSZ into two parts, eastern and western, with different geodynamic behaviors (Byrne et al. 1992), the possibility of a very large earthquake due to the cascading rupture of both segments could not be ignored, assuming the rupture spreads from the west to the east or vice versa. Therefore, it is necessary to consider the MSZ as an integrated seismic region, although not very likely, in order to consider all possible scenarios for thorough tsunami hazard estimation.

In previous researches conducted, such as the tsunami hazard analysis for the coasts of Oman ( El-Hussain et al., 2016), an integrated rupture in Makran with a magnitude of more than 9.0 with a branch weight of 0.15 has been considered. Also, in the seismic hazard analysis report of the cities of Abu Dhabi, Dubai and Ras-al-Khaimah in the United Arab Emirates (Aldama-Bustos et al. 2009), a weight of 0.05 is attributed to the scenario corresponding to the cascading rupture of the MSZ.

In present study, taking into account the above discussion a logic tree branch with a low weight $(0.15)$ is considered to account for the possibility of a cascading rupture along two MSZ segments (the unsegmented branch in the logic tree of Fig. 2).

\section{2-5 Seismic coupling coefficient}

The seismic coupling coefficient $\chi_{s}$ is the ratio of seismic moment released by earthquakes to seismic moment stored between plates as a result of relative tectonic movement within a subduction zone.

The seismic moment rate is generally calculated by dividing the total seismic moment obtained from recorded earthquakes in an instrumental catalogue by the catalogue's time period. It is worth noting that the estimation of seismic moment rate is inherently uncertain due to the long return periods of major earthquakes that might not be reported in instrumental catalogues. Actually, a century of seismic activity in a subduction zone does not adequately represent the long-term seismicity, and the approximation based on it, results in lower coupling coefficients. Taking into account the scarcity of seismicity in the Makran region, seismic coupling of the MSZ is another open question.

The measurement of the inter-seismic strain accumulation rate, which gives the inter-seismic moment rate $\left(X_{g}\right)$, has been easily accomplished due to the rise in the number of GPS stations (Scholz and Campos (2012)). The shortcomings of the traditional catalogue-based method for calculating the seismic coupling rate, which is primarily due to the lack of large earthquakes recorded in seismic catalogues, have been resolved by the novel geodetic approach. Note that although the coupling ratio calculated by the classical approach yields the released moment, the geodetic coupling rate gives the total energy stored within the tectonic plates. Both methods are equal in the long run if the coupling rate remains constant over time. The inconsistency between the two concepts discussed above highlights earthquakes that have been ignored in seismic catalogues and should be explored further using historical resources or paleo-seismic methods (Scholz and Campos (2012)). One source of uncertainty in the estimation of coupling rate is the error in the approximation of coupled surface area $\left(A_{c}\right)$, which is the region of the contacting plates where seismic slip occurs (seismogenic area). The length of this area $\left(L_{c}\right)$ is inferred from the length of the subducting segment. However, the end pieces from both sides are often ignored. A more important source of uncertainty is the estimation of the coupled area's width $\left(W_{c}\right) . W_{c}$ is determined between the accretionary wedge and the brittle-plastic transition zone. According to Scholz and Campos (2012), the brittle- 
plastic transition normally occurs where the temperature reaches $350^{\circ} \mathrm{C}$. Another transition zone exists below this temperature, which is where slow-slip events usually occur. Further below, the plates can freely slip without any coupling.

There are three ways to calculate the width of the coupled field, $W_{c}$. First, by observing the location of background seismic activity, second, based on the slipped areas of large previous earthquakes, and third, by inverting the GPS data

The first two methods have a 30 percent uncertainty (Scholz and Campos 2012), while the third method has a lower uncertainty and is more effective in determining the deep seismic edge. Because the top seismic edge is usually located far from the coast and the GPS stations are located along the coast, the data provided by the GPS stations does not provide a good constraint for the top edge depth. Scholz and Campos (2012) used both GPS data and seismological observations to calculate the amount of seismic coupling in many subduction zones around the world. According to their study, the coupling rate is between 0 and 1, with an average value of 0.6.

In the other study, Heuret et al. (2011) reported the coupling coefficient based only on the previous century seismicity, and the slip-rate values across the subducting area. It is worth noting that Heuret et al (2011) used a shear modulus of $\mathrm{G}=50 \mathrm{GPa}$ instead of the more common values of $\mathrm{G}=30 \mathrm{GPa}$ (Hanks and Kanamori 1979; Davies et al. 2017) or $\mathrm{G}=40 \mathrm{GPa}$ (Scholz and Campos 2012), which resulted in a $20 \%$ reduction in the coupling coefficient values compared to what was reported by Scholz and Campos (2012). The seismic coupling by Heuret et al. (2011) was found to be uncorrelated $(\mathrm{R}=0.17)$ with the subduction velocity, which is consistent with the observation of Pacheco et al. (1993).

In a comprehensive study by GEM group (Berryman et al. 2015), the coupling ratio in the MSZ was assumed to be between 0.3 and 0.7. Note that in (Berryman et al. 2015) the coupling ratio was based on expert opinion rather than modelling. As emphasized by Byrne et al (1992), because the creeping regime exists at every subduction zone, we assumed two low and high creeping branches for both eastern and western Makran. Furthermore, the fact that some faults have a cycle of seismic activity and silence was taken into consideration when assessing branch weights .

Davies et al. (2017) considered subduction rate as $19 \mathrm{~mm} / \mathrm{yr}$ and used three different seismic slip rates of 5.4, 9.0 , and $13.0 \mathrm{~mm} / \mathrm{yr}$, corresponding to coupling rates of $0.3,0.5$, and 0.7 , respectively. Furthermore, maximum magnitudes of 8.1, 8.8, and 9.5 were assumed, accordingly.

Ghadimi et al. (2021, submitted.) computed the long-term crustal flow and forecast of seismicity for the MSZ, using a kinematic finite element technique. They investigated the possibility of creep in western Makran, by comparing two different models with the coupling rates of 0 (means free slipping) and 1 (corresponds to a totally locked fault) for the western Makran. The results of the temporarily locked model indicated about $1 \sim 3 \mathrm{~mm} / \mathrm{yr}$ higher rate of shortening than the other models with the steady creeping subduction. Also, the predicted interseismic velocities and seismicity from the creeping model are more accurate for the western Makran.

In this article, based on the results of Ghadimi et al. (2021, submitted) and the review presented above, we used a coupling ratio of 0.3 for western, 0.6 for eastern, and two values of 0.3 and 0.45 for an unsegmented model. Additional conservative branches are also included in the logic tree for the eastern, western, and unsegmented model, with a pessimistic coupling coefficient of 1.0, indicating a fully coupled subduction (Fig. 2)

\section{2-6 Updip rupture depth}

The shallow aseismic-seismic transition depth $\left(d_{s}\right)$ estimated by Pacheco et al. (1993) as $d_{s}=10 \mathrm{~km}$ for all subduction zones, was adopted by the Slab1.0 Model (Hayes et al. 2012). Slab 2.0. (Hayes et al. 2018) takes a different approach based on the seismicity depth of subduction zones, with a minimum $d_{s}=9 \mathrm{~km}$ (Tonga subduction zone), a maximum $d s=16 \mathrm{~km}$ (Kamchatka subduction zone), and an average $d s=12 \mathrm{~km}$. In contrast to other active subduction zones around the globe (Smith et al. 2012), the MSZ has a thick sediment layer (3-7 km) (McAdoo et al. 2004), so an active depth deeper than the global average seems reasonable. For the MSZ, considering the limited seismic data obtained in the subduction interface, Slab 2.0 (Hayes et al. 2018) reports shallow and deep seismogenic depths of $13 \mathrm{~km}$ and $40 \mathrm{~km}$, respectively. Taking into account the above discussion and considering depth distribution of local seismicity in the region (Ah. Rashidi et al., 2020) (Fig. 3), the updip rupture depth in Makran has been set at $14 \mathrm{~km}$ as an optimistic value.

Prior to the Indian Ocean Tsunami of 2004 and the Tohoko Tsunami of 2011, the possibility of an earthquake rupture extending up to the seabed was thought to be unlikely. However, clear evidence suggests that the rupture 
was extended up, nearly to the subduction trench in both cases, and was shallower than what previously thought. Although the rupture is unlikely to nucleate in shallow depths, it is now widely accepted that deeper events could extend seaward (Smith et al, 2012). Accordingly, the probabilistic study of tsunami hazards must account for seabed rupture. Therefore, in addition to the optimistic value of $14-\mathrm{km}$, we consider 3-km as an alternate updip rupture depth for buried rupture scenarios. In fact, the 14-km updip rupture depth assumes that the rupture would not spread into unconsolidated shallow sediments; whereas the 3-km ones takes this into account.

We also consider trench faulting as another possible option, suggesting the rupture could extend up to the seabed. Splay faulting is also considered in this study according to section 27 (for different models of faulting means buried, splay and trench-breaching see Gao et al., 2018). Thermal and geodetic constraints can help determine the deep extent of the seismogenic zone, but expert debates are generally determining the shallow extent extent (e.g. Stirling et al, 2012 for Hikurangi subduction interface).

\section{2-7 Splay faulting}

Splay faults are secondary faults rising from the plate interface and extend up to the seafloor. They are usually detected in seismic reflection profiles and exist in many of the subduction zones, including Makran (Grando and McClay 2007; Smith et al. 2012; Mokhtari 2015). Splay faults can slip during large subducting events or independently produce earthquakes. They are usually shallow (or even reach the surface) and steeper than the megathrust and can locally and significantly displace the seafloor and therefore the initial water surface. Subsequently, they can have a substantial contribution in tsunami hazard at local scale. The 1946 Nankai tsunami is a good exemplar of splay fault tsunamis (Cummins and Kaneda 2000). The effect of splay faulting in enhancing the 1960 Chile, 1964 Alaska and 2004 Indian Ocean tsunamis has been also reported (e.g. Plafker 1972; Sibuet et al. 2007). Splay faulting was brought up as a secondary tsunami source that increased the run-up caused by the 1945 Makran tsunami (Heidarzadeh et al. 2009). The dip of a splay fault can be landward or seaward in which they both can enhance tsunami wave amplitudes. However, a seaward dipping fault can generate a stronger tsunami as the shallower part of the fault is toward the sea.

Priest et al. (2010) took into account the effect of splay faulting in evaluating tsunami hazard of local earthquakes in the Cascadia subduction zone. To do so, they developed a logic-tree and assigned different weights for their scenarios, including splay faulting. In the case of splay fault scenario, the slip is partitioned between the megathrust and splay fault. Priest et al. (2010) showed that the splay faulting amplifies the tsunami wave height between 6 to $31 \%$ and the run-up between 2 to $20 \%$. The results of tsunami numerical simulation for different models of faulting (buried, splay and trench-breaching) in Northernmost Cascadia (Gao et al. 2018) shows that the splay faulting model generate higher tsunami waves (50 to 100\%) than the commonly-used model of buried rupture. Heidarzadeh et al. (2009) studied the effect of splay faulting on tsunami amplitudes in Makran. Their outcome for a combined tsunami source of the eastern Makran segment and a splay fault indicates the increase of seabed displacement by 1.5 times and tsunami amplitude by 2 times at some locations.

In this study, we incorporate the effect of splay faulting into the tsunami hazard along the coastline of Iran. We consider a landward splay fault dip of $35^{\circ}$ that connects to the megathrust (main fault) at a depth of about 14 $\mathrm{km}$ (Fig. 4). We partition the seismic moment of the rupture between the main fault and the splay fault in which the splay faulting portion ranges from $10 \%$ for the largest scenarios to $32 \%$ in the case of smallest scenarios. 


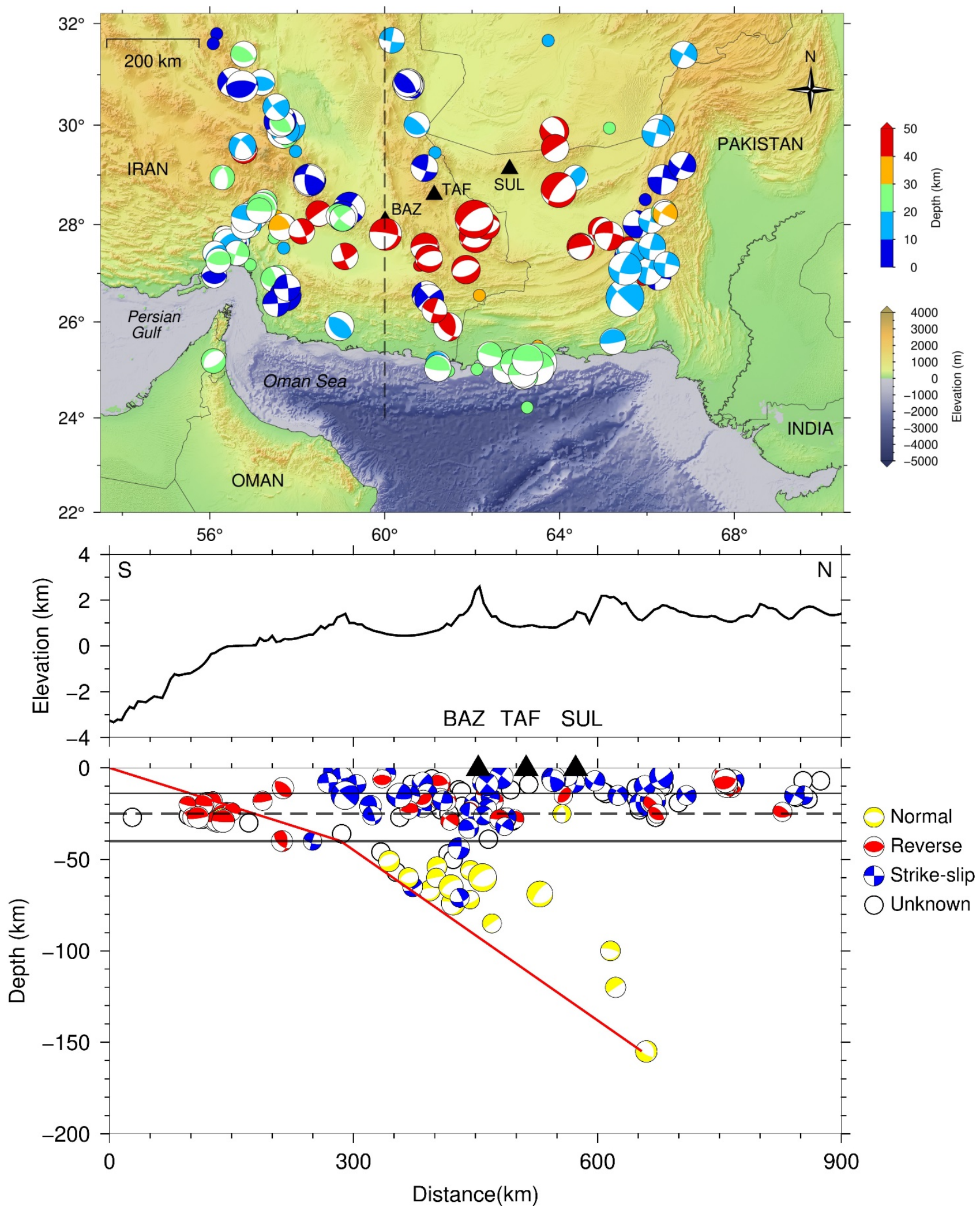

Fig. 3 Top: Focal mechanism and depth distribution of Makran seismicity. Bottom: Section of Makran seismicity, based on catalogs with more reliable depths including, normal faults, reverse faults, strike-slip faults, and without mechanism. A line is drawn with a dip angle of 8 degrees from latitude 24 degrees north, which indicates the boundary of the oceanic lithosphere of the sinking Arabian plate below Eurasia. Depths of 14 and $40 \mathrm{~km}$ are marked by two continuous horizontal lines. The ratio of vertical scale to horizontal scale is 1 to 3 . The triangles show the volcanoes of Bazhman, Taftan, and Sultan 


\section{2-8 Fault rupture locations and slip distributions}

Since the occurrence of an earthquake with different magnitudes, in any parts of the MSZ is possible, different fault locations along the subduction interface should be considered to cover the entire seismic zone. In this way, more than 155 fault locations which completely cover the MSZ are assumed in this study (Fig. 5).

Previous studies (Goda et al. 2014; Ruiz et al. 2015; Sun et al. 2018; e.g. Crempien et al. 2020; Momeni et al. 2020) have shown the amplifying effect of heterogeneous slip distribution on the generated tsunami wave height. In order to model the heterogeneous slip on the fault, the finite fault technique (Gallovič and Brokešová 2004) has been used in this study. The number of subfaults along the length and dip directions is adjusted based on the average subfault size of $\sim 15 \mathrm{~km}( \pm 5 \mathrm{~km})$.

The lengths and widths of the rupture plane for each earthquake scenario and the mean and maximum slip values are calculated using appropriate empirical scaling relationships (Allen and Hayes 2017).

To consider aleatory uncertainty of slip distribution, for each fault location, 12 heterogeneous slip scenarios are generated using k-2 kinematic source modelling (Gallovič and Brokešová 2004). The Heterogeneous slip scenarios are generated considering limitations of average and maximum slipping on fault which are calculated using Allen and Hayes (2017) scaling relationships. Also taking into account the previous inversion based earthquake rupture models of interface events (Mai and Thingbaijam 2014), in generating heterogeneous slip scenarios, placement of slip asperities in the upper one third of the fault in more than 3 of 12 scenarios are not allowed. In other words, in most of scenarios, slip asperities are located at the deeper parts of the fault. Fig. 6 shows six samples of generated slip distribution scenarios in this study corresponding to $\mathrm{Mw} 8.0, \mathrm{Mw} 8.4$, and Mw 9.0.
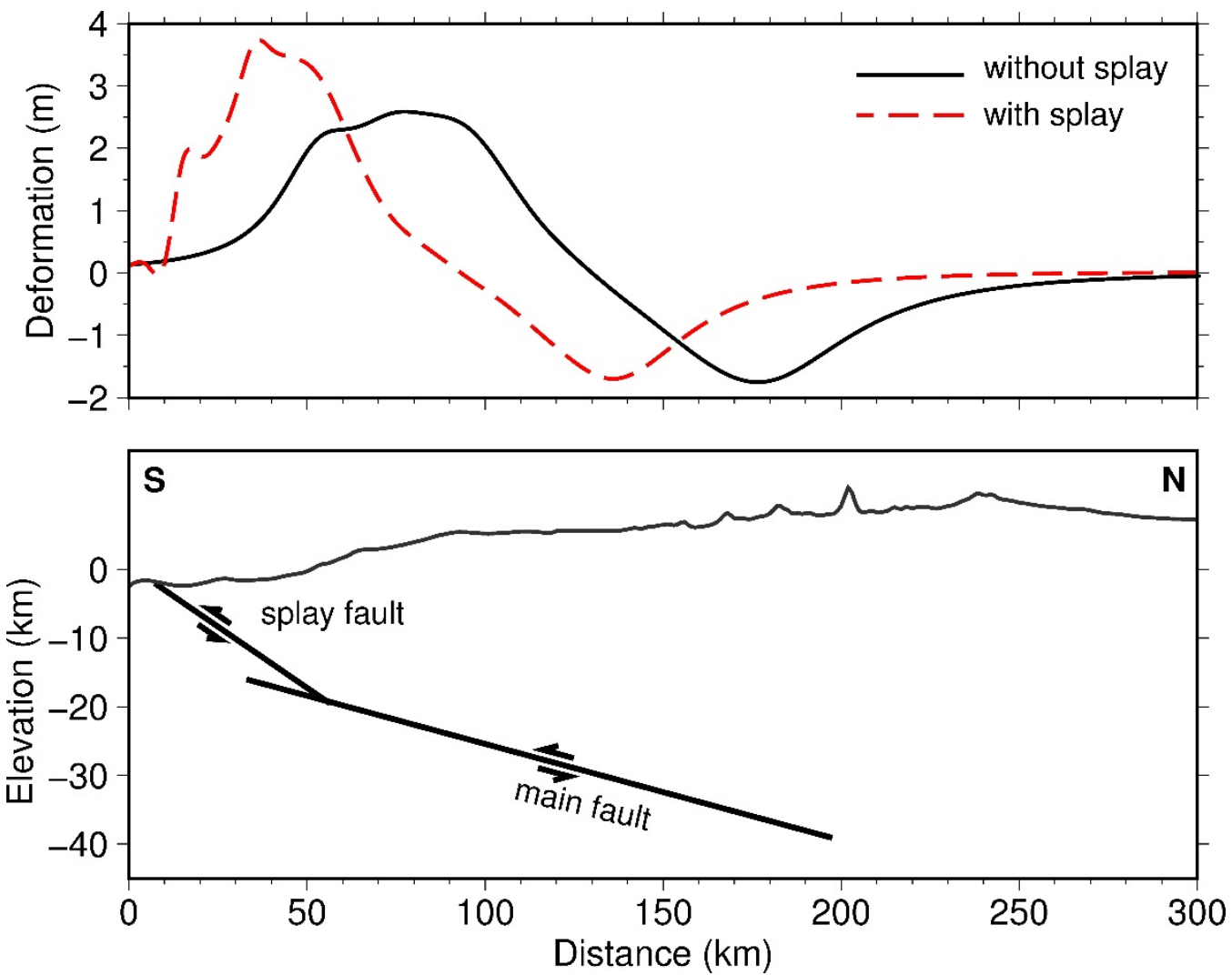

Fig. 4 Comparison of the seabed displacement in two scenarios with and without splay fault, symbolic representation of splay fault geometry modeled in Makran seismic hazard simulation 


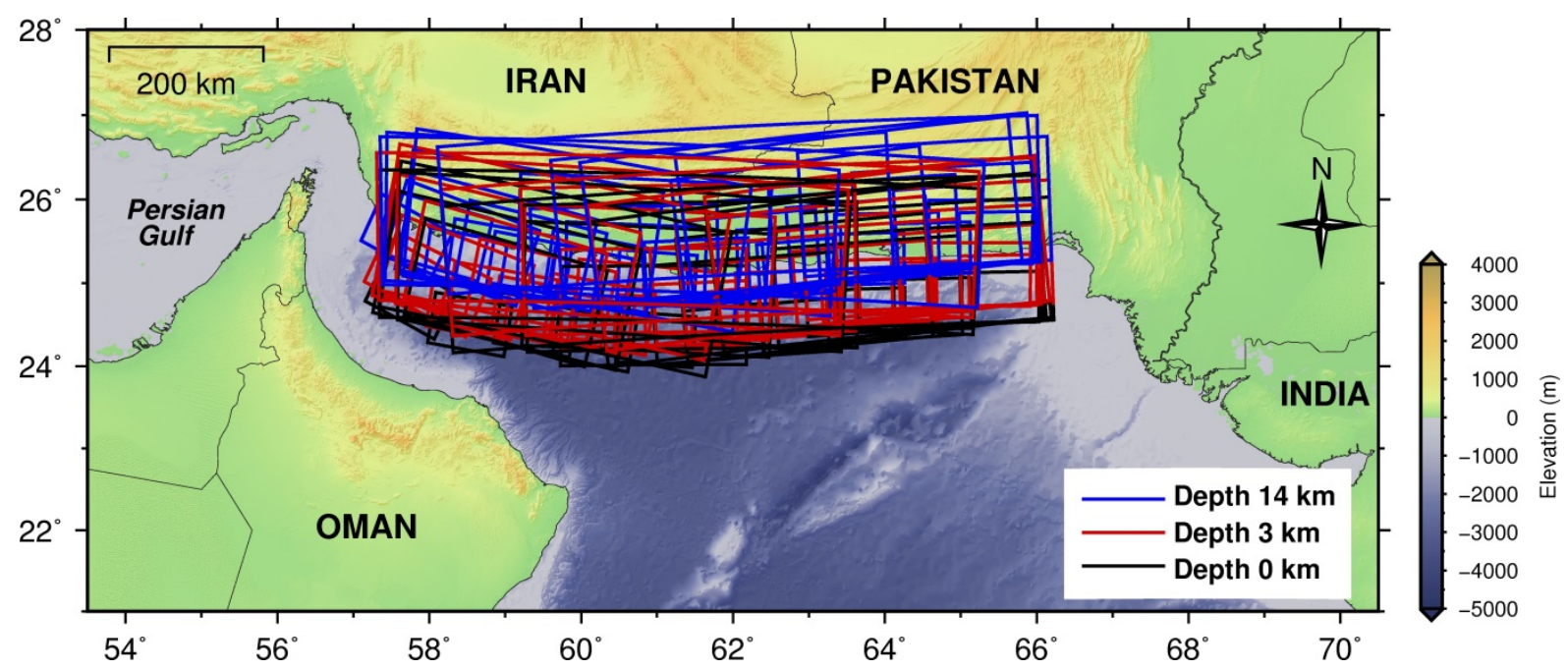

Fig. 5 Considered fault locations in this study which completely cover the MSZ

523

524

525

526

527

528

529

530

531

532

533

534

535

536

\section{3_Probabilistic tsunami hazard analysis (PTHA)}

Due to the uncertainties of the seismic magnitude, fault location, slip distribution, seismicity depth, and splay fault we have considered a number of scenarios according to Table 2 and have performed numerical simulation for each one (section 3-1).

Based on the results of these simulations, for each magnitude $m$ and each wave height $z_{0}$, the probability of the wave height exceeding a given value of $z_{0}, P\left(Z>z_{0} \mid m\right)$ can be obtained. This probability is obtained by integration over the aleatory uncertainties representing the natural uncertainty in the expected wave amplitudes given a specific magnitude of tsunamigenic earthquake.

Hazard curves are obtained for different branches of logic-tree representing epistemic uncertainty.

For each branch of the logic tree, the annual exceedance rate $v\left(z_{0}\right)$ is calculated based on the following equation:

$$
v\left(z_{0}\right)=\sum_{m=M_{\min }}^{M_{\max }} \lambda(m) P\left(Z>z_{0} \mid m\right)
$$

Where $\lambda(m)$ is the annual frequency of earthquakes with magnitudes $m \pm \Delta m / 2$. The magnitude bin size $\Delta m$ is set as 0.2 magnitude units (see Table 3 ).

In the logic tree branches where the activities of the eastern and western zones of Makran are considered different, the random slip distributions, related seabed deformations, and resulting tsunamis for each zone are simulated separately during calculation of the exceedance rate. For these branches, the exceedance rate $v\left(z_{0}\right)$ is calculated based on the following:

$$
v\left(z_{0}\right)=\sum_{n=1}^{N_{\text {Segments }}} \sum_{m=M_{\min }}^{M_{\max }} \lambda_{n}(m) P\left(Z>z_{0} \mid m\right)
$$

Where $N_{\text {Segments }}$ is equal to 2 (eastern and western MSZs) and $\lambda_{n}(m)$ is the annual frequency of earthquakes on source $n$ with magnitudes between $m \pm \Delta m / 2$.

The calculation of $\mathrm{P}\left(\mathrm{Z}>z_{0} \mid \mathrm{m}\right)$ can be done in two ways. The first method is to form a set of simulated wave heights at the desired point, which are obtained by considering all scenarios with in the magnitude bin $m \pm \Delta m / 2$. Then a wave height like $z_{0}$ is selected and the number of wave heights that are greater than $z_{0}$ is counted in the 
set. The ratio of the number of scenarios with wave heights greater than $z_{0}$ to the total number of the scenarios provides the intended probability at the desired point, which is called here as the real probability.

In the second method, it is assumed that the desired probability follows the log-normal distribution (e.g. Kulkarni et al., 2016). Therefore, by calculating the mean and standard deviation of the set of simulated waveheights, the log-normal distribution is fitted to them.

Fig. 7 shows the comparison of the real probability distribution and log-normal distribution in calculating $\mathrm{P}$ $\left(\mathrm{Z}>z_{0} \mid \mathrm{m}\right)$, which is presented according to the simulation results for a point on the coast of Chabahar and shows that two approaches give similar results, at least for probabilities higher than 0.05 .

Then based on the assumptions of the logic tree, we calculated the probabilistic tsunami hazard curves for all of its branches and formed the statistical population for different hypotheses of the exceedance rate. Based on the formed sample population, for each wave height, we calculated exceedance rate at the average, $16 \%, 50 \%$ and $84 \%$ percentiles of distribution.

Fig. 8 shows an example of these calculations for a point located on the coast of Chabahar. By reading the wave height in the values of $1 / 475$ and $1 / 2475$ from the output hazard curve, it is possible to calculate the value of the wave height in the 475-year and 2475-year return periods, at different levels of confidence. It is worth noting that a group of hazard curves relating to the eastern Makran scenarios are located below others in Fig. 8. The reason for the lower hazard is that Chabahar is in the western Makran, whereas all of the source zones in those scenarios are located in the eastern Makran, therefore, the source-receiver distance is comparatively longer for this group.
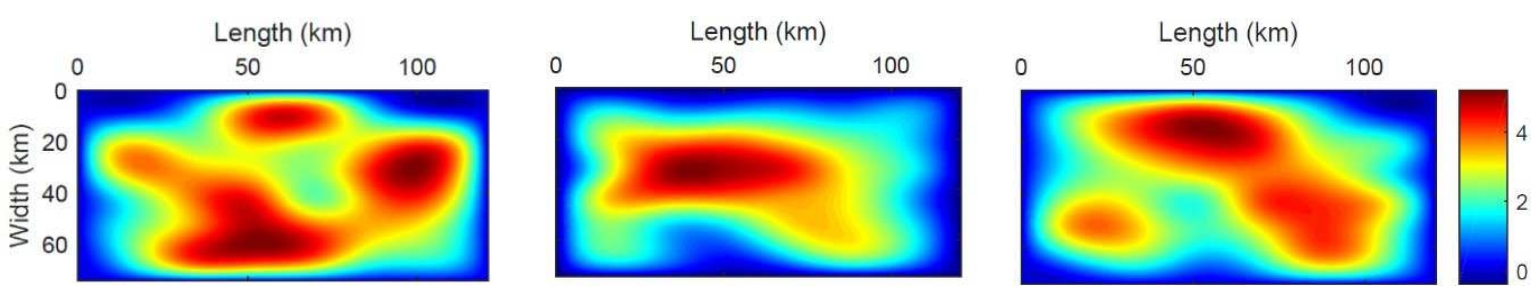

a. $M w 8$

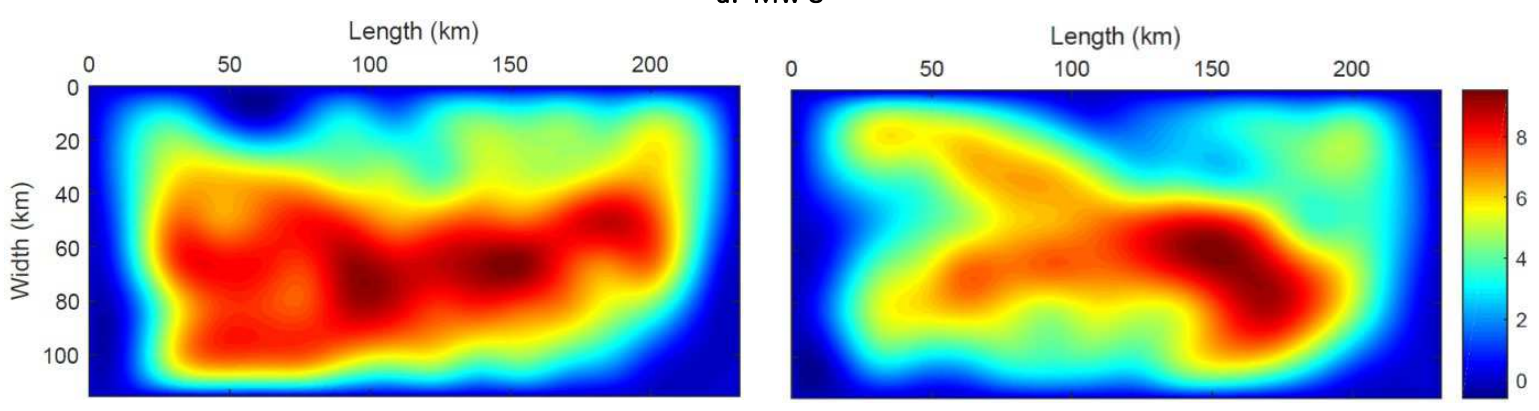

b. $M w 8.4$

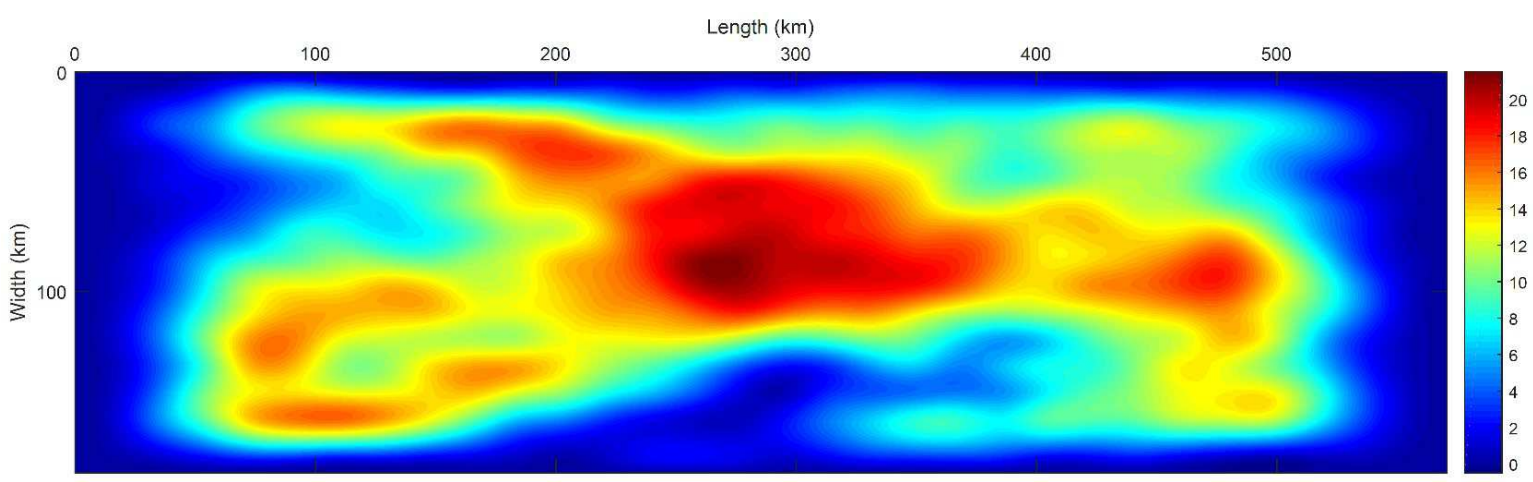

c. $\mathrm{Mw} 9.0$

Fig. 6 Six examples of generated slip distribution scenarios in this study a. Mw 8.0, b. Mw 8.4, and c Mw 9.0 
Table 2. Number of numerically simulated scenarios due to different fault locations, rupture depth/geometry, and fault slip

distribution uncertainties. It is notable that item "number of fault depth / geometry scenarios" includes splay faults too.

\begin{tabular}{ccccc}
\hline Seismic magnitude & $\begin{array}{c}\text { Number of fault } \\
\text { locations }\end{array}$ & $\begin{array}{c}\text { Number of fault depth/ } \\
\text { geometry scenarios }\end{array}$ & $\begin{array}{c}\text { Number of } \\
\text { slip distribution scenarios }\end{array}$ & Total \\
\hline $7.7-7.9$ & 10 & 4 & 12 & 480 \\
\hline $7.9-8.1$ & 7 & 4 & 12 & 336 \\
\hline $8.1-8.3$ & 6 & 4 & 12 & 288 \\
\hline $8.3-8.5$ & 5 & 4 & 12 & 196 \\
\hline $8.5-8.7$ & 4 & 4 & 12 & 144 \\
\hline $8.7-8.9$ & 3 & 4 & 12 & 96 \\
\hline $8.9-9.1$ & 2 & 4 & 12 & 96 \\
\hline $9.1-9.3$ & 2 & 4 & $\mathbf{1 8 7 2}$
\end{tabular}

\section{3-1- Tsunami numerical modelling}

The tsunami phenomenon consists of three main phases: generation, propagation, and inundation. Underwater earthquakes are the main cause of about $80 \%$ of tsunamis (Løvholt 2017). Therefore, we consider only these kind of earthquakes as tsunami sources.

If the total rupture time of an earthquake is much shorter than the period of the tsunami wave, the seabed displacement is considered as an instantaneous motion. This method is conventionally called passive seismic generation (Dutykh et al. 2006; Kervella et al. 2007). By using this method, static (rather than dynamic) displacement is considered for the seabed due to earthquake. It is also assumed that the initial amplitude of the tsunami wave is exactly the same as the amount of vertical displacement of the seabed, because the water of this vast area affected by fault sliding cannot be drained within the rupture time (Steketee 1958). Therefore, the initial conditions for the propagation of tsunami waves are obtained by transferring the final vertical static displacement of the seabed to the water surface. Okada's (1992) closed form solution is used to obtain vertical displacement in the seabed. According to this solution, in a semi-infinite homogeneous environment, if the fault is rectangular and the amount and direction of slip are constant everywhere on the fault, a closed form solution can be written to obtain displacement anywhere in the space. For the faults with non-constant slip, the fault is divided into a number of sub-faults, that can be treated separately and the final displacement of the seabed is equal to the sum of all subfault displacements based on the superposition principle.

The source rupture modeling parameters used in this study are listed in Table 3. After tsunami waves are generated, they propagate through the water. The most common equations to describe the propagation of tsunami waves are the shallow water equations, which are derived from mass and momentum continuity. These equations assume that the horizontal scale (wavelength) is much larger than the vertical scale (water depth). The second assumption for these equations is that the viscous effect is ignored. As a result of these two assumptions, the horizontal velocity of the waves will be much higher than the vertical velocity of the waves, the horizontal velocity of the wave will be constant at depth and the pressure will be hydrostatic.

This study adopts COMCOT (COrnell Multi-grid COupled Tsunami Model; Liu et al., 1998) as the kernel to perform tsunami modeling. COMCOT supports both linear/nonlinear shallow water equations for tsunami simulations with the two-grid nesting scheme for flexible computational grid sizes and time steps crossing multiple layers and moving boundary scheme for calculating coastal inundation areas and flood depths. On the one hand, in deep-water regions where the nonlinear effect is ignored, the linear shallow water equations are used for simulating a proposed tsunami from its original source to nearshore regions. On the other hand, in shallowwater regions where tsunami waves are amplified by the shoaling effect and bathymetry effect (see, e.g., Imamura et al., 1998; Kajiura \& Suto, 1990), the nonlinear equations are adopted for calculating nearshore tsunamis. It is noted here that both linear and nonlinear shallow water equations are conducted in the spherical coordinate.

As the wavelength of tsunami waves changes due to the water depth, the grid sizes and time steps shall be modified accordingly. Thus, we consider the three-layer nested-grid configuration to simulate tsunami waves propagating from offshore to nearshore (see Fig. 9). 

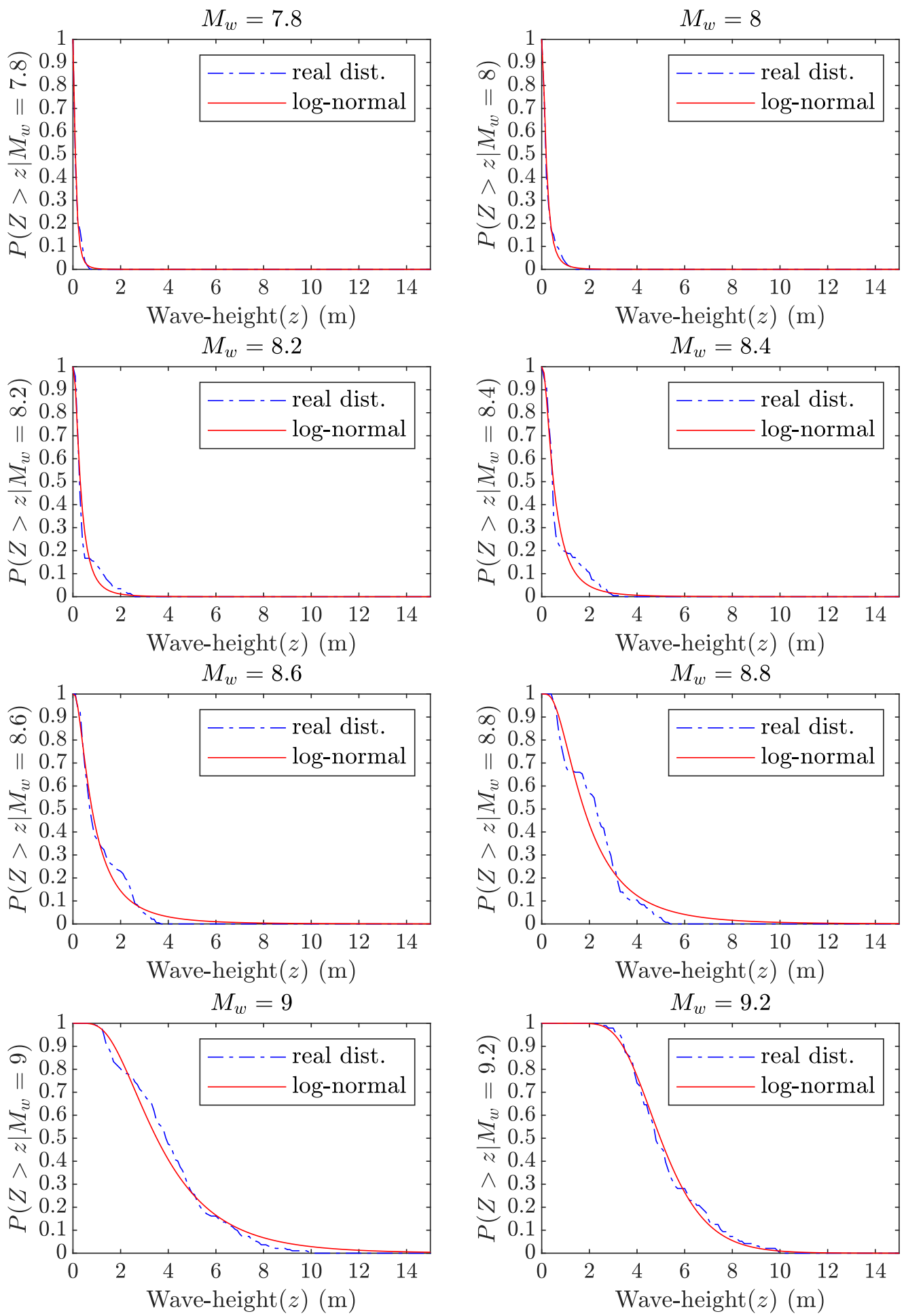


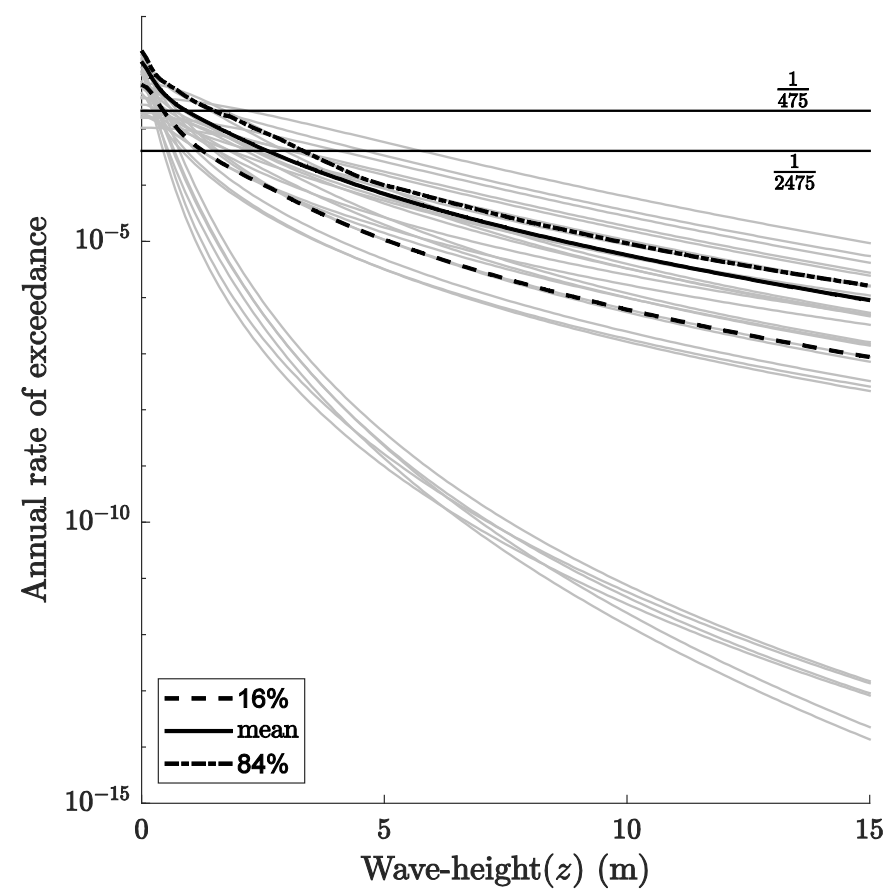

Fig. 8 An example of calculating exceedance rate at the $16 \%, 50 \%$ and $84 \%$ levels of distribution for a point located on the coast of Chabahar, for the 475 and 2475 years return period. Note that a group of hazard curves relating to the eastern Makran scenarios are stacked below the others

The grid sizes of the first, second, and third layers are 30,15, and 5 arc-seconds, respectively. The bathymetry data for the first and second layers comes from the General Bathymetric Charts of the Oceans (GEBCO) 2020 digital grid atlas (IOC, 2003; Weatherall et al., 2015), which has the spatial resolution of 15 arc-seconds. The data used in the third layer comes from local data in the Chabahar area with a high spatial resolution of 3 arc-seconds. It should be mentioned that we use the Manning's coefficient equal to 0.025 as a standard value for coastal water nearshore bottom friction in layer 2 and 3 . The computational settings of the nested-grid configuration can be found in Table 4.

The calculation of the water amplitudes at the shoreline using low-resolution bathymetry data may underestimate the tsunami impact (Kamigaichi 2009, 2015).

Since in most of the coastal areas of western Makran (except the Chabahar Bay) bathymetry data are only available with a maximum resolution of 15 seconds, the Green's law is applied in this study, ensuring the calculated shoreline results would not be less than the actual expected values. According to the Green's law (conservation of energy), the tsunami wave height farther from the shore is used to approximate the tsunami wave height on the shore according to equation (7).

$$
h_{0}=\sqrt[4]{\frac{d_{1}}{d_{0}}} h_{1}
$$

$\mathrm{h}$ and $\mathrm{d}$ denote the tsunami wave height and see depth, and indices ' 0 ' and ' 1 ', respectively, represent the value on the shoreline and offshore point.

In this study, the height of water on the shoreline is calculated by converted values from a depth of 50 and a depth of $10 \mathrm{~m}$. The final result for coastal line is presented using these two values with reasonable weights. 
Table 3. The source rupture modeling parameters used in this study

\begin{tabular}{ll}
\hline Parameter & Values/Ranges \\
\hline Magnitude (Mw) & $7.8 \sim 9.2$ \\
\hline Dip angle (degree) & 8 (for the main fault) \\
Rake angle & $90^{\circ}$ \\
\hline Length & $65-790(\mathrm{~km})$ \\
Width & $50-195(\mathrm{~km})$ \\
Average slip & $0.8-10.5(\mathrm{~m})$ \\
Maximum slip & $2.4-39(\mathrm{~m})$ \\
\hline Slip distribution & Heterogeneous \\
$\begin{array}{l}\text { Strike direction } \\
\text { Fault depth } \\
\text { (Top of fault) }\end{array}$ & $260-330$ \\
\hline
\end{tabular}

641

642

643

644

645

646

647

648

649

650

651

Table 4. The bathymetry data, the grid sizes, the time steps, and the type of equations for three layers used in this study

\begin{tabular}{cccccc}
\hline Layer number & Bathymetry data & $\begin{array}{c}\text { grid size } \\
(\Delta x \text { and } \Delta y)\end{array}$ & Time step & $\begin{array}{c}\text { Manning's } \\
\text { coefficient }\end{array}$ & Governing Equations \\
\hline 1 & Gebco_15 sec_2020 & $30 \mathrm{sec}$ & 12 & - & Linear SWE \\
\hline 2 & Gebco_15 sec_2020 & $15 \mathrm{sec}$ & 12 & 0.025 & Nonlinear SWE \\
\hline 3 & Local data_3 sec & $5 \mathrm{sec}$ & 12 & 0.025 & Nonlinear SWE \\
\hline
\end{tabular}

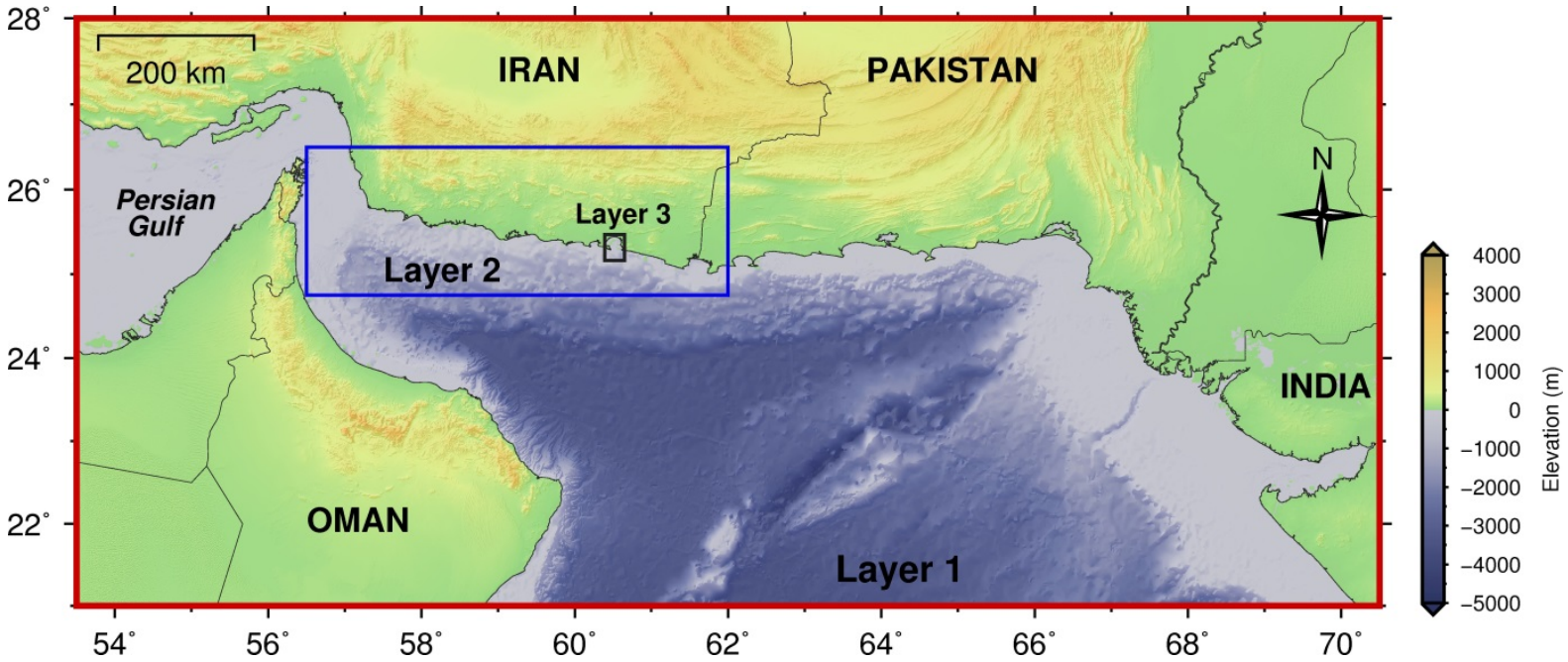

Fig. 9 Nested grid with three layers used in this study. Layer 1, 30-second grid size (large Rectangle); Layer 2, 15-second grid size (medium Rectangle); and Layer 3,5-second grid size (small Rectangle) 

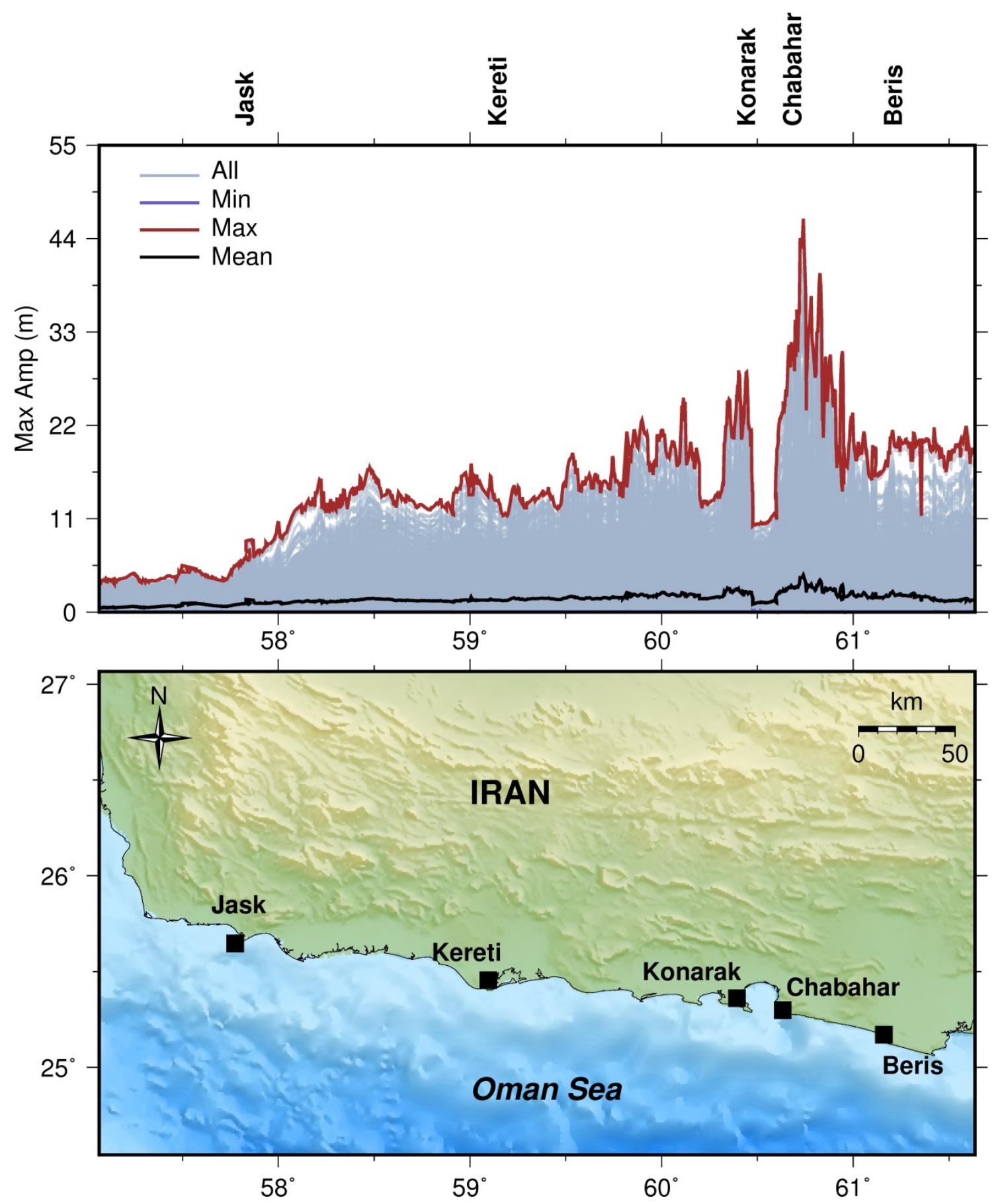

\section{3-2- Earth subsidence}

Where the seismic source is a local subduction event (as is possible in the MSZ), in addition to the uplift of the sea floor, it can cause land subsidence in areas near the coast or on the coast (ASCE7, 2016, Ruiz et al., 2015).

A number of limit scenarios were considered to select the time required to simulate. The modeling results show that the maximum amplitude of seismic waves for all stations occurs before the first 6 hours and the simulation time of 6 hours is a good choice.

The results of all numerical modeling (1872 scenarios) are shown in Fig. 10. After completing the numerical simulations, the PTHA calculation is done according to section 3.

To take into account this effect, the change in the ground elevation per point source is calculated using the Okada 
(1992) method and the superposion principle is empolyed for extended fault ruptures. The subsidence is added to the tsunami wave height on the shore and at the shoreline to retrieve the final results (ASCE7, 2016).

In this article, in order to have more realistic assessment of the tsunami water height relative to the reference ground level, we perform probabilistic hazard calculations once for the height of water from the water free surface and once for the earth subsidence, and sum up the results of the two, conservatively. Actualy this is somehow conservative, as we know that two maximums do not occurr simultaneously.

In each modeling, if there was an uplift at any point along the shoreline instead of subsidence, the subsidence value was considered zero. The results of earth subsidence for western Makran coast, in the vicinity of Sistan va Baluchestan and Hormozgan provinces, have been calculated in two return periods of 475 and 2475 years with two levels of average confidence and eighty-four percent (Fig. 13 and Fig. 14).

According to this calculation, the maximum subsidence of the coastline with average level of confidence is $0.15 \mathrm{~m}$ and $1 \mathrm{~m}$ for return periods of 475 and 2475 years, respectively.

Moreover, the maximum subsidence of the coastline with $84 \%$ level of confidence is $0.5 \mathrm{~m}$ and $1.23 \mathrm{~m}$ for return periods of 475 and 2475 years, respectively.

\section{4- Results and discussion}

In this study, the final results of tsunami wave height for western Makran coast have been calculated in the form of uniform hazard maps in two return periods of 475 and 2475 years with two confidence levels of mean and eighty-four percent (Fig. 13 and Fig. 14).

The output presented in this study for each $15 \mathrm{~km}$ section of the Makran coast is equal to the maximum amount of probabilistic analysis observed in all points located in that section.

Since the return period of 2475 years is more compatible with the long recurrence times of large plate boundary earthquakes in the MSZ, it is recommended to use the tsunami wave heights of 2475 years (at the mean level) for structural design peurposes. This is consistent with the "maximum considered tsunami" returun period addopted by the ASCE7 (2016) for the United States coastal regions. The more conservative level of $84 \%$ could be applied for critical structures.

Comparison of the output results of our simulations (before applying the probabilistic hazard analysis algorithm) with simulated scenarios with similar dip angle (8 to 15 degrees) in other places such as the scenarios of the 1707 Nankai earthquake in Japan (Furumura et al. 2011) and the coast of Sumatra, Indonesia (McCloskey et al. 2008) indicates the similarity of the range of obtained wave height.

Moreover, the accuracy of the probabilistic hazard analysis process is examined and compared with the results for different coupling coefficients (lower pairing coefficient; lower wave height), different return period (lower return period; lower wave height) and different confidence levels (lower confidence level; Lower wave height).

Finally, it is a good idea to compare the results with some previous regional or global studies, devoted to the PTHA in the MSZ. In comparisons it should be kept in mind that the subsidence effects are only included in our results.

The probabilistic hazard maps reported by Burbidge et al. (2009) are divided into "high hazard" and "low hazard" maps based on different assumed maximum magnitudes. They noted that the actual hazard occurs between these two scenarios. The western segment of the MSZ is not included as a source zone in their low-hazard scenario, because of the fact that there is no certain knowledge of its potential to produce large tsunamigenic earthquakes. The highest tsunami amplitudes (in the water depth of $100 \mathrm{~m}$ ) from these two low and high hazard scenarios along the coastline of Iran are 0.3 and $2.7 \mathrm{~m}$, Thus, for a return period of 2000 years, applying the Green's Law approximation (Kamigaichi, 2015), the coastal tsunami amplitudes would be 1.0 and $8.5 \mathrm{~m}$, respectively. In a more recent study on the PTHA of the Makran region, Hoechner et al. (2016) give tsunami wave heights of 1 and $3 \mathrm{~m}$ (for the return period of 500 years) and 4 and $11 \mathrm{~m}$ (for the return period of 2500 years), at the Jask and Chabahar cities that are comparable with our results.

Davies et al. (2017) conducted a PTHA on the global scale including the MSZ and showed that the probabilistic tsunami wave height along the Makran coastlines is generally about the same range, but it decreases towards the Strait of Hormuz. In their results, tsunami wave amplitude varies between 1.0 to $5.0 \mathrm{~m}$ and between 5.0 to $10.0 \mathrm{~m}$ for return periods of 500 and 2500 years, respectively, which is comparable with our results. 


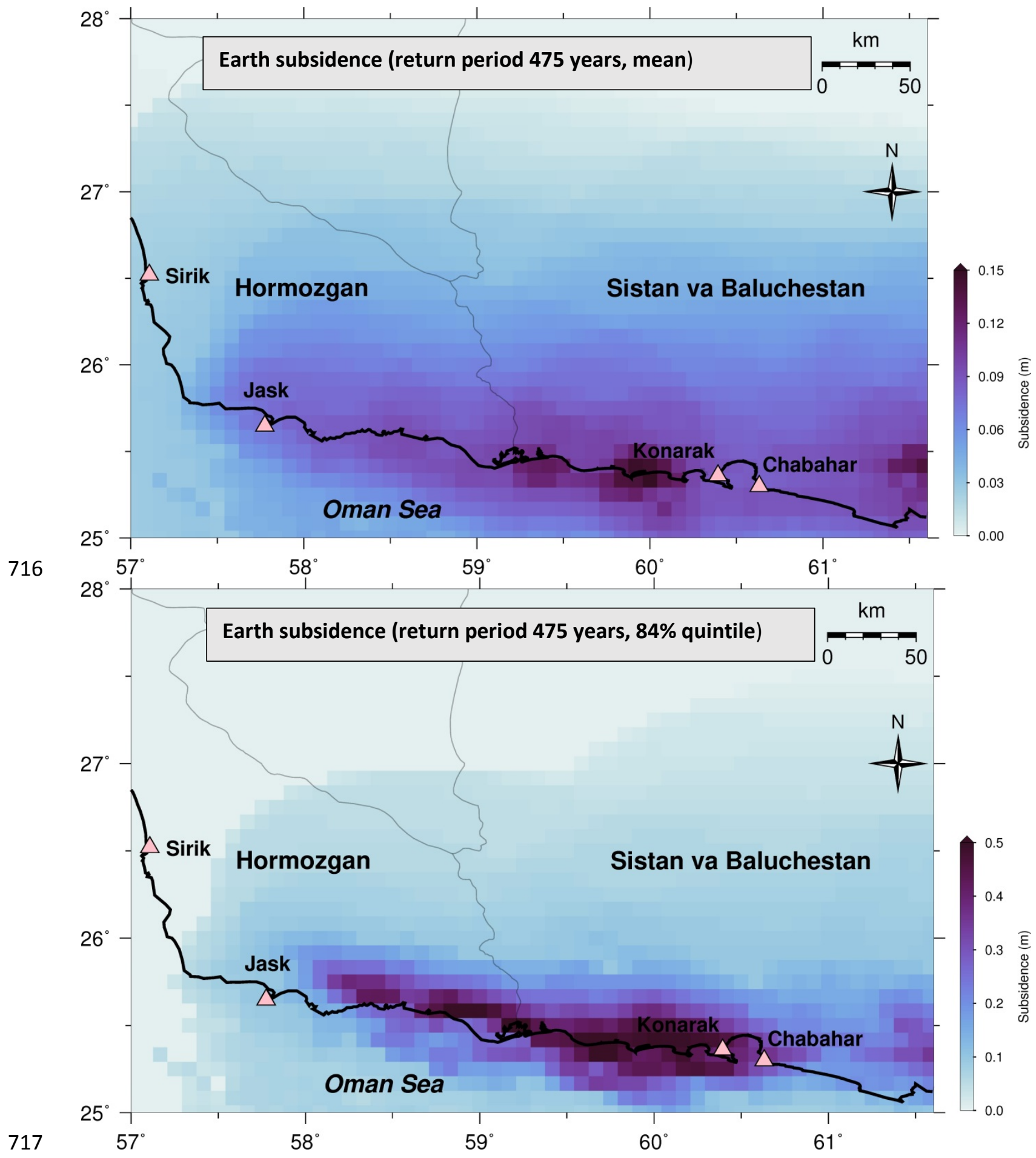

Fig. 11 Earth subsidence plans for western Makran corresponding to a return period of 475 years with two levels of average confidence and eighty-four percent 


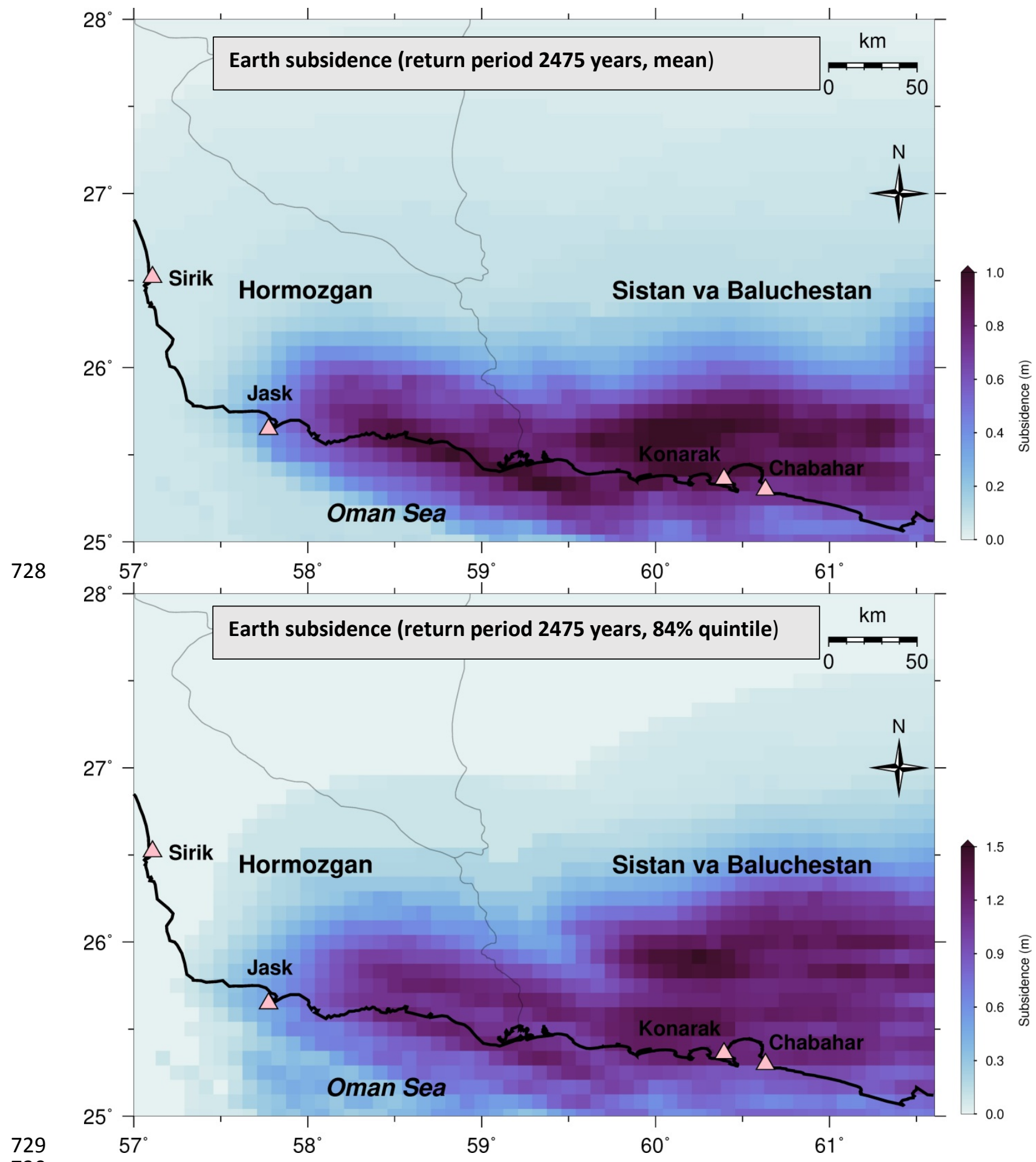

Fig. 12 Earth subsidence plans for western Makran corresponding to a return period of 2475 years with two levels of average confidence and eighty-four percent 

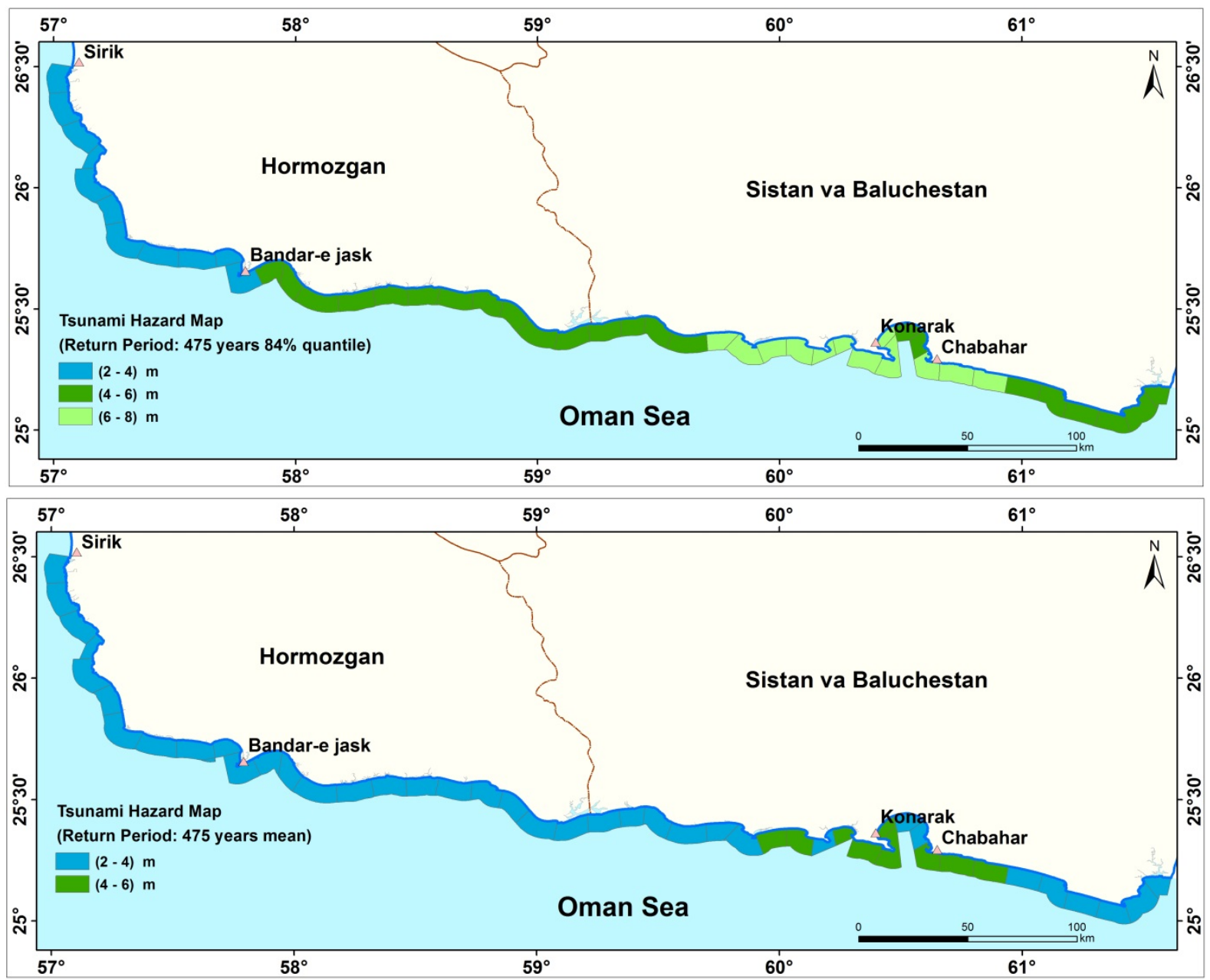

Fig. 13 Uniform hazard plans for western Makran corresponding to a return period of 475 years with two confidence levels 

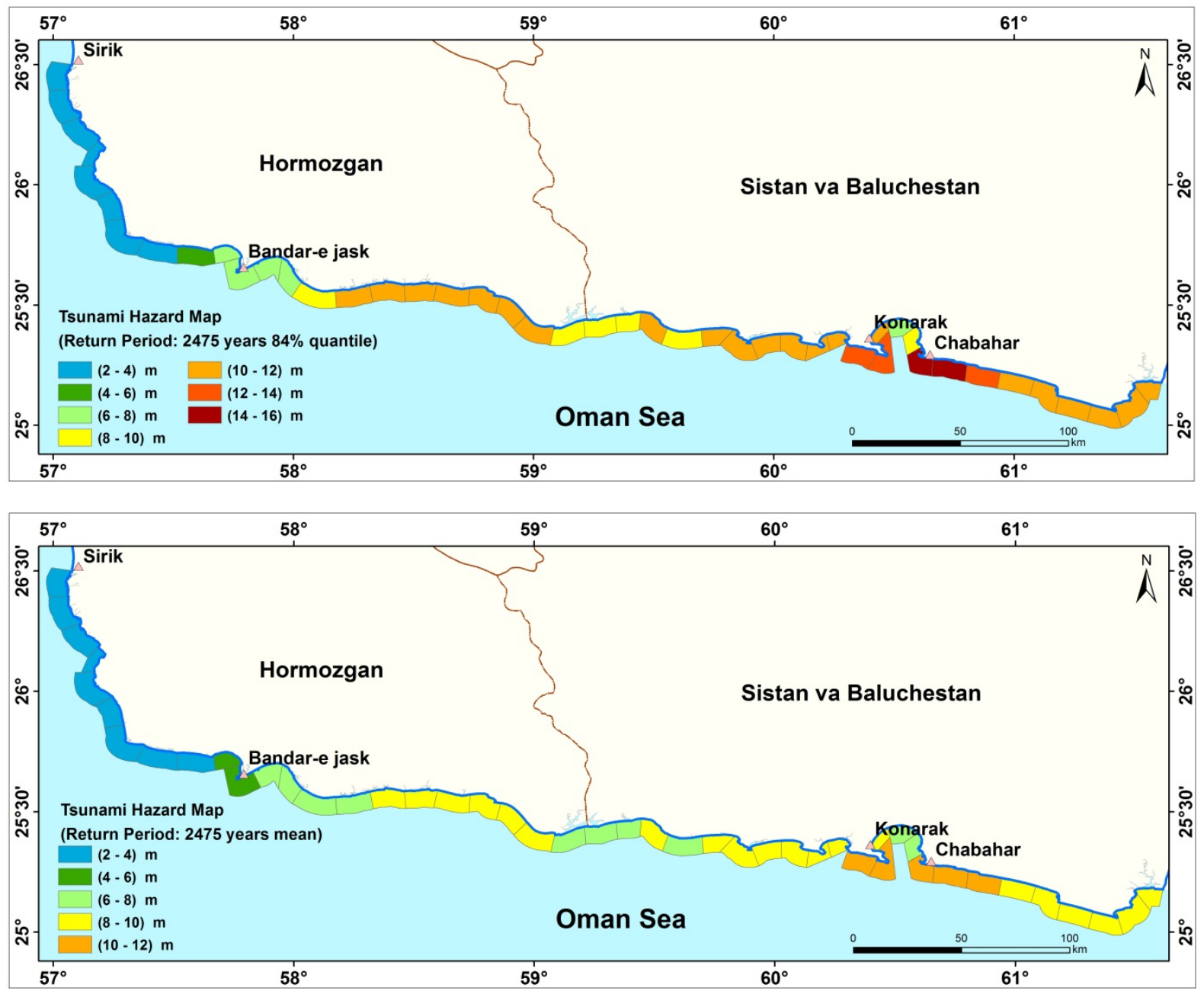

Fig. 14 Uniform hazard plans for western Makran corresponding to a return period of 2475 years with two confidence levels of mean and eighty-four percent

\section{5- Conclusions}

This study presents the first tsunami hazard zonation in the coastal area of western Makran using probabilstic tsunami hazard assesment, including all possible uncertainities and earth subsidence effects. The results are expressesed in terms of uniform hazard maps for two return periods of 475 and 2475 years at two confidence levels of average and eighty-four percent. As tsunamis generated by far-field tectonic sources cause very little effect on this part, we consider only tsunamis of earthquake origin generated in the MSZ.

The uncertainty of maximum seismic magnitude, scaling relations, earthquake occurrence model, continuity of seismic zone, seismic coupling coefficient, depth of rupture, splay fault, fault locations, and fault slip distribution are included in PTHA calculation for this region. We use the COMCOT tsunami modelling code to simulate 1872 scenarios.

The result shows that Chabahar and Sirik are respectively exposed to the highest and lowest probable water heights due to the tsunami.

In this study we do our best to have reliable assessment for PTHA in the west MSZ. However, it is important to consider its limitations and try to reduce them as possible in future studies. In this study, we consider underwater earthquakes as the only sources for tsunami, but it seems appropriate to study the investigate seabed landslides as another possible causes of tsunami and their combination with earthquakes in MSZ. In addition, in our study we ignore the dynamic interaction between the tides and tsunami waves. Therefore, to use the probabilistic tsunami water height presented in this study it is necessary to add the value of corresponding maximum tidal height at any location, conservatively. More accurate results can be achieved by considering this dynamic interaction. Finally, 
we should mention the importance role of high quality bathymetry and topography data for more accurate PTHA results, especially for simulation of inundation and runup that we hope to consider in our future studies.

\section{References}

Abrahamson NA, Bommer JJ (2005) Probability and uncertainty in seismic hazard analysis. Earthq spectra 21:603-607

Aldama-Bustos G, Bommer JJ, Fenton CH, Stafford PJ (2009) Probabilistic seismic hazard analysis for rock sites in the cities of Abu Dhabi, Dubai and Ra's Al Khaymah, United Arab Emirates. Georisk 3:1-29. https://doi.org/10.1080/17499510802331363

Allen TI, Hayes GP (2017) Alternative rupture-scaling relationships for subduction interface and other offshore environments. Bull Seismol Soc Am 107:1240-1253. https://doi.org/10.1785/0120160255

Ambraseys NN, Melville CP (1982) A history of Persian earthquakes. Cambridge university press

Anderson JG, Luco JE (1983) Consequences of slip rate constraints on earthquake occurrence relations. Bull Seismol Soc Am 73:471-496

Annaka T, Satake K, Sakakiyama T, et al (2007) Logic-tree approach for Probabilistic Tsunami Hazard Analysis and its applications to the Japanese coasts. Pure Appl Geophys 164:577-592. https://doi.org/10.1007/s00024-006-0174-3

Atkinson GM, Goda K (2011) Effects of seismicity models and new ground-motion prediction equations on seismic hazard assessment for four Canadian cities. Bull Seismol Soc Am 101:176-189. https://doi.org/10.1785/0120100093

Bayrak Y, Yilmaztürk A, Öztürk S (2002) Lateral variations of the modal (a/b) values for the different regions of the world. J Geodyn 34:653-666. https://doi.org/10.1016/S0264-3707(02)00037-6

Benito MB, Lindholm C, Camacho E, et al (2012) A new evaluation of seismic hazard for the Central America Region. Bull Seismol Soc Am 102:504-523. https://doi.org/10.1785/0120110015

Berryman K, Wallace L, Hayes G, et al (2015) The GEM faulted earth subduction interface characterisation project. GNS Science

Blaser L, Krüger F, Ohrnberger M, Scherbaum F (2010) Scaling relations of earthquake source parameter estimates with special focus on subduction environment. Bull Seismol Soc Am 100:2914-2926. https://doi.org/10.1785/0120100111

Burbidge DR, Cummins PR, Mleczko R, et al (2009) A Probabilistic Tsunami Hazard Assessment of the Indian Ocean Nations. Geosci Aust Prof Opin 78-79

Byrne DE, Sykes LR, Davis DM (1992) Great Thrust Earthquakes and Aseismic Slip Along the Plate Boundary of the Makran motion in the form of earthquakes may occur in a variety ( e .g ., southern Chile ), while still others have experienced no of ways at subduction zones. Some margins produ. J Geophys Res 97:449-478

Crempien JGF, Urrutia A, Benavente R, Cienfuegos R (2020) Effects of earthquake spatial slip correlation on variability of tsunami potential energy and intensities. Sci Rep 10:1-10. https://doi.org/10.1038/s41598020-65412-3

Cummins PR, Kaneda Y (2000) Possible splay fault slip during the 1946 Nankai earthquake

Davies G, Griffin J, Løvholt F, et al (2017) A global probabilistic tsunami hazard assessment from earthquake sources. Geol Soc Spec Publ 456:219-244. https://doi.org/10.1144/sp456.5

Deif A, El-Hussain I (2012) Seismic moment rate and earthquake mean recurrence interval in the major tectonic boundaries around Oman. J Geophys Eng 9:773-783. https://doi.org/10.1088/1742-2132/9/6/773

Dutykh D, Dias F, Kervella Y (2006) Linear theory of wave generation by a moving bottom. Comptes Rendus Math 343:499-504

El-Hussain I, Omira R, Al-Habsi Z, et al (2018) Probabilistic and deterministic estimates of near-field tsunami hazards in northeast Oman. Geosci Lett 5:. https://doi.org/10.1186/s40562-018-0129-4

El-Hussain I, Omira R, Deif A, et al (2016) Probabilistic tsunami hazard assessment along Oman coast from submarine earthquakes in the Makran subduction zone. Arab J Geosci 9:. https://doi.org/10.1007/s12517016-2687-0

Frohling E, Szeliga W (2016a) GPS constraints on interplate locking within the Makran subduction zone. Geophys J Int 205:67-76. https://doi.org/10.1093/gji/ggw001

Frohling E, Szeliga W (2016b) GPS constraints on interplate locking within the Makran subduction zone. Geophys Suppl to Mon Not R Astron Soc 205:67-76

Furumura T, Imai K, Maeda T (2011) A revised tsunami source model for the 1707 Hoei earthquake and simulation of tsunami inundation of Ryujin Lake, Kyushu, Japan. J Geophys Res Solid Earth 116:. https://doi.org/10.1029/2010JB007918

Gallovič F, Brokešová J (2004) The k-2 Rupture Model Parametric Study: Example of the 1999 Athens Earthquake. Stud Geophys Geod 48:589-613. https://doi.org/10.1023/B:SGEG.0000037473.70906.08 
Gao D, Wang K, Insua TL, et al (2018) Defining megathrust tsunami source scenarios for northernmost Cascadia. Nat Hazards 94:445-469. https://doi.org/10.1007/s11069-018-3397-6

Ghadimi Moghaddam H, Khodaverdian A, Zafarani H Long term fault slip rates, distributed deformation rates and forecast of seismicity in the Makran Region

Goda K, Mai PM, Yasuda T, Mori N (2014) Sensitivity of tsunami wave profiles and inundation simulations to earthquake slip and fault geometry for the 2011 Tohoku earthquake. Earth, Planets Sp 66:1-20. https://doi.org/10.1186/1880-5981-66-105

Grando G, McClay K (2007) Morphotectonics domains and structural styles in the Makran accretionary prism, offshore Iran. Sediment Geol 196:157-179. https://doi.org/10.1016/j.sedgeo.2006.05.030

Hanks TC, Kanamori H (1979) Eo. 84:2348-2350

Hayes GP, Moore GL, Portner DE, et al (2018) Slab2, a comprehensive subduction zone geometry model Hayes GP, Wald DJ, Johnson RL (2012) Slab1.0: A three-dimensional model of global subduction zone geometries. J Geophys Res Solid Earth 117:1-15. https://doi.org/10.1029/2011JB008524

Heidarzadeh M, Kijko A (2011) A probabilistic tsunami hazard assessment for the Makran subduction zone at the northwestern Indian Ocean. Nat Hazards 56:577-593. https://doi.org/10.1007/s11069-010-9574-X

Heidarzadeh M, Pirooz MD, Zaker NH, et al (2008) Historical tsunami in the Makran Subduction Zone off the southern coasts of Iran and Pakistan and results of numerical modeling. Ocean Eng 35:774-786. https://doi.org/10.1016/j.oceaneng.2008.01.017

Heidarzadeh M, Pirooz MD, Zaker NH (2009) Modeling the near-field effects of the worst-case tsunami in the Makran subduction zone. Ocean Eng 36:368-376. https://doi.org/10.1016/j.oceaneng.2009.01.004

Heuret A, Lallemand S, Funiciello F, et al (2011) Physical characteristics of subduction interface type seismogenic zones revisited. Geochemistry, Geophys Geosystems 12:1-26. https://doi.org/10.1029/2010GC003230

Hoechner A, Babeyko AY, Zamora N (2016) Probabilistic tsunami hazard assessment for the Makran region with focus on maximum magnitude assumption. Nat Hazards Earth Syst Sci 16:1339-1350. https://doi.org/10.5194/nhess-16-1339-2016

Hydro BC (2012) Probabilistic Seismic Hazard Analysis (PSHA) Model, Volumes 1, 2, 3 and 4. BC Hydro

Ioc IHO (2003) BODC: Centenary Edition of the GEBCO Digital Atlas, published on CD-ROM on behalf of the Intergovernmental Oceanographic Commission and the International Hydrographic Organization as part of the General Bathymetric Chart of the Oceans. Br Oceanogr Data Centre, Liverpool, UK 52:

Jaiswal RK, Singh AP, Rastogi BK (2009) Simulation of the Arabian Sea Tsunami propagation generated due to 1945 Makran Earthquake and its effect on western parts of Gujarat (India). Nat Hazards 48:245-258. https://doi.org/10.1007/s11069-008-9261-3

Kagan YY (2002) Seismic moment distribution revisited: II. Moment conservation principle. Geophys J Int 149:731-754. https://doi.org/10.1046/j.1365-246X.2002.01671.x

Kamigaichi O (2009) Tsunami forecasting and warning. In: Extreme Environmental Events

Kamigaichi O (2015) Tsunami Forecasting and Warning. Encycl Complex Syst Sci 1-38. https://doi.org/10.1007/978-3-642-27737-5_568-3

Kervella Y, Dutykh D, Dias F (2007) Comparison between three-dimensional linear and nonlinear tsunami generation models. Theor Comput fluid Dyn 21:245-269

Kopp C, Fruehn J, Flueh ER, et al (2000) Structure of the Makran subduction zone from wide-angle and reflection seismic data. Tectonophysics 329:171-191. https://doi.org/https://doi.org/10.1016/S00401951(00)00195-5

Kulkarni RB, Youngs RR, Coppersmith KJ (1984) Assessment of confidence intervals for results of seismic hazard analysis. In: Proceedings of the eighth world conference on earthquake engineering. pp 263-270

Kulkarni V, Arcos MEM, Alcinov T, et al (2016) Probabilistic tsunami hazard assessment for a site in eastern Canada. Pure Appl Geophys 173:3719-3755

Løvholt F (2017) 2 . Tsunami Hazard and Risk Assessment. 1-9

Løvholt F, Pedersen G, Bazin S, et al (2012) Stochastic analysis of tsunami runup due to heterogeneous coseismic slip and dispersion. J Geophys Res Ocean 117:1-17. https://doi.org/10.1029/2011JC007616

Maggi A, Jackson JA, Priestley K, Baker C (2000) A re-assessment of focal depth distributions in southern Iran, the Tien Shan and northern India: Do earthquakes really occur in the continental mantle? Geophys J Int 143:629-661. https://doi.org/10.1046/j.1365-246X.2000.00254.x

Mai PM, Thingbaijam KKS (2014) SRCMOD: An Online Database of Finite-Fault Rupture Models. Seismol Res Lett 85:1348-1357. https://doi.org/10.1785/0220140077

McAdoo BG, Capone MK, Minder J (2004) Seafloor geomorphology of convergent margins: Implications for Cascadia seismic hazard. Tectonics 23:. https://doi.org/https://doi.org/10.1029/2003TC001570

McCloskey J, Antonioli A, Piatanesi A, et al (2008) Tsunami threat in the Indian Ocean from a future megathrust earthquake west of Sumatra. Earth Planet Sci Lett 265:61-81. https://doi.org/10.1016/j.eps1.2007.09.034 
Meletti C, D'Amico V, Martinelli F (2010) Homogeneous determination of maximum magnitude

Mokhtari M (2015) The role of splay faulting in increasing the devastation effect of tsunami hazard in Makran, Oman Sea. Arab J Geosci 8:4291-4298. https://doi.org/10.1007/s12517-014-1375-1

Momeni P, Goda K, Heidarzadeh M, Qin J (2020) Stochastic analysis of tsunami hazard of the 1945 Makran subduction zone MW 8.1-8.3 earthquakes. Geosci 10:1-20. https://doi.org/10.3390/geosciences10110452

Muldashev IA, Sobolev S V. (2020) What Controls Maximum Magnitudes of Giant Subduction Earthquakes? Geochemistry, Geophys Geosystems 21:. https://doi.org/10.1029/2020GC009145

Murotani S, Satake K, Fujii Y (2013) Scaling relations of seismic moment, rupture area, average slip, and asperity size for M 9 subduction-zone earthquakes. Geophys Res Lett 40:5070-5074. https://doi.org/10.1002/grl.50976

Musson RMW (2009) Subduction in the Western Makran: the historian\&\#039;s contribution. J Geol Soc London 166:387 LP - 391. https://doi.org/10.1144/0016-76492008-119

Neetu S, Suresh I, Shankar R, et al (2011) Trapped waves of the 27 November 1945 Makran tsunami: Observations and numerical modeling. Nat Hazards 59:1609-1618. https://doi.org/10.1007/s11069-0119854-0

Okada Y (1992) Internal deformation due to shear and tensile faults in a half-space. Bull Seismol Soc Am $82: 1018-1040$

Pacheco JF, Sykes LR, Scholz CH (1993) Nature of seismic coupling along simple plate boundaries of the subduction type. J Geophys Res 98:. https://doi.org/10.1029/93jb00349

Pajang S, Cubas N, Letouzey J, et al (2021) Seismic hazard of the western Makran subduction zone: Insight from mechanical modelling and inferred frictional properties. Earth Planet Sci Lett 562:116789. https://doi.org/https://doi.org/10.1016/j.epsl.2021.116789

Papazachos B, Scordilis E, Panagiotopoulos D, et al (2004) GLOBAL RELATIONS BETWEEN SEISMIC FAULT PARAMETERS AND MOMENT MAGNITUDE OF EARTHQUAKES. Bull Geol Soc Greece 36:1482-1489

Penney C, Tavakoli F, Saadat A, et al (2017) Megathrust and accretionary wedge properties and behaviour in the Makran subduction zone. Geophys J Int 209:1800-1830. https://doi.org/10.1093/gji/ggx126

Pisarenko VF, Sornette D (2004) Statistical detection and characterization of a deviation from the GutenbergRichter distribution above magnitude 8. Pure Appl Geophys 161:839-864. https://doi.org/10.1007/s00024-003-2475-0

Plafker G (1972) Alaskan earthquake of 1964 and Chilean earthquake of 1960: Implications for arc tectonics. J Geophys Res 77:901-925

Power WL (2013) Review of tsunami hazard in New Zealand (2013 update). Ministry of Civil Defence and Emergency Management

Priest GR, Goldfinger C, Wang K, et al (2010) Confidence levels for tsunami-inundation limits in northern Oregon inferred from a 10,000-year history of great earthquakes at the Cascadia subduction zone. Nat Hazards 54:27-73. https://doi.org/10.1007/s11069-009-9453-5

Rashidi A, Zafarani H, Tatar M (2020a) Geometric characteristics of the Makran's subduction zone. Tectonics 12:

Rashidi A, Zaher ·, Shomali H, et al (2020b) Tsunami hazard assessment in the Makran subduction zone. 100:861-875. https://doi.org/10.1007/s11069-019-03848-1

Ruff L, Kanamori H (1980) Seismicity and the subduction process. Phys Earth Planet Inter 23:240-252. https://doi.org/https://doi.org/10.1016/0031-9201(80)90117-X

Ruiz JA, Fuentes M, Riquelme S, et al (2015) Numerical simulation of tsunami runup in northern Chile based on non-uniform k-2 slip distributions. Nat Hazards 79:1177-1198. https://doi.org/10.1007/s11069-0151901-9

Scholz CH, Campos J (2012) The seismic coupling of subduction zones revisited. J Geophys Res Solid Earth 117:1-22. https://doi.org/10.1029/2011JB009003

Schwartz SY (1999) Noncharacteristic behavior and complex recurrence of large subduction zone earthquakes. J Geophys Res Solid Earth 104:23111-23125. https://doi.org/10.1029/1999jb900226

Sibuet J-C, Rangin C, Le Pichon X, et al (2007) 26th December 2004 great Sumatra-Andaman earthquake: Coseismic and post-seismic motions in northern Sumatra. Earth Planet Sci Lett 263:88-103

Skarlatoudis AA, Somerville PG, Thio HK (2016) Source-scaling relations of interface subduction earthquakes for strong ground motion and tsunami simulation. Bull Seismol Soc Am 106:1652-1662. https://doi.org/10.1785/0120150320

Smith G, McNeill L, Henstock IJ, Bull J (2012) The structure and fault activity of the Makran accretionary prism. J Geophys Res Solid Earth 117:1-17. https://doi.org/10.1029/2012JB009312

Steketee JA (1958) ON VOLTERRA'S DISLOCATIONS IN A SEMI-INFINITE ELASTIC MEDIUM. Can J Phys 36:192-205. https://doi.org/10.1139/p58-024

Stewart JP, Chiou S-J, Bray JD, et al (2002) Ground motion evaluation procedures for performance-based 


\section{Statements \& Declarations}

977

978

\section{Competing Interests}

Not applicable

design. Soil Dyn Earthq Eng 22:765-772. https://doi.org/https://doi.org/10.1016/S0267-7261(02)00097-0

Strasser FO, Arango MC, Bommer JJ (2010) Scaling of the Source Dimensions of Interface and Intraslab Subduction-zone Earthquakes with Moment Magnitude. Seismol Res Lett 81:941-950. https://doi.org/10.1785/gssrl.81.6.941

Sun Y-S, Chen P-F, Chen C-C, et al (2018) Assessment of the peak tsunami amplitude associated with a large earthquake occurring along the southernmost Ryukyu subduction zone in the region of Taiwan. Nat Hazards Earth Syst Sci 18:2081-2092

Tajima R, Matsumoto Y, Si H, Irikura K (2013) Comparative study on scaling relations of source parameters for great earthquakes in inland crusts and on subducting plate boundaries. Zisin 66:31-45

Thingbaijam KKS, Mai PM, Goda K (2017) New empirical earthquake source-scaling laws. Bull Seismol Soc Am 107:2225-2246. https://doi.org/10.1785/0120170017

THIO HK, SOMERVILLE P, ICHINOSE G (2007) Probabilistic Analysis of Strong Ground Motion and Tsunami Hazards in Southeast Asia. J Earthq Tsunami 01:119-137. https://doi.org/10.1142/s1793431107000080

Wang Y-J, Chan C-H, Lee Y-T, et al (2016) Probabilistic seismic hazard assessment for Taiwan. Terr Atmos Ocean Sci 27:325-340

Weatherall P, Marks KM, Jakobsson M, et al (2015) A new digital bathymetric model of the world's oceans. Earth Sp Sci 2:331-345

Wells DL, Coppersmith KJ (1994) New empical relationship between magnitude, rupture length, rupture width, rupture area, and surface displacement. Bull Seismol Soc Am 84:974-1002

Youngs RR, Coppersmith KJ (1985) Implications of fault slip rates and earthquake recurrence models to probabilistic seismic hazard estimates. Bull Seismol Soc Am 75:939-964

\section{Funding}

The present study was carried out within the frame-work of the project "Tsunami and Seismic hazard assessment for the Makran region." Funding for this project was provided by the Plan and Budget Organization of the Islamic Republic of Iran (PBO).

985 